\title{
Measuring subnational trade competitiveness
}

\author{
Robert A. Huber* Yannick Stiller ${ }^{\dagger} \quad$ Andreas Dür
}

\begin{abstract}
Much research has tried to measure the competitiveness of territorial units such as countries and subnational regions. We propose new measures of subnational trade competitiveness that reflect the economic focus of regions on their country's comparative advantage. Our approach starts with data on the revealed comparative advantage of countries at the industry level. We then combine these measures with data on the employment structure of regions to arrive at measures of subnational trade competitiveness. In total, we offer data for 1,212 regions across 62 countries and over a time period of 21 years. In this paper, we introduce our measures and provide descriptive evidence that shows the plausibility of these measures. We also discuss some of the many research questions that these data can be used to address.
\end{abstract}

Acknowledgements: This research has received funding from the European Research Council (ERC) under the European Union's Horizon 2020 research and innovation programme (grant agreement No 724107). We also thank statistical offices in various countries for giving us access to their data.

\section{Introduction}

Ever since Michael Porter published a highly influential study on The Competitive Advantage of Nations in 1990 (Porter 1990), much research has analyzed the competitiveness of territorial units. This has led to various rankings of the competitiveness of countries (e.g. Schwab 2019), regions (Annoni and Dijkstra 2019; Huggins et al. 2014), and even cities (Huggins, Thompson, and Prokop 2019). Over time, criticisms of the original efforts (most prominently by Krugman 1994) have led to various improvements in the conceptualization of territorial competitiveness (Berger and Bristow 2009; Birnie et al. 2019; Budd and Hirmis 2004).

We contribute to this large literature by proposing new measures of what we call subnational trade competitiveness. Our measures capture the extent to which a region's economic structure is aligned with the comparative advantage of the country to which it belongs. The

\footnotetext{
*University of Salzburg; robert.huber@sbg.ac.at

${ }^{\dagger}$ University of Salzburg; yannick.stiller@sbg.ac.at

‡University of Salzburg; andreas.duer@sbg.ac.at
} 
resulting data on regions' trade competitiveness is of interest for many research areas across various disciplines. Illustratively, it allows for research on questions as diverse as: does trade integration (for example via trade agreements) affect regions differently depending on their trade competitiveness? Which policies increase or decrease a region's trade competitiveness? To what extent do individuals take into account the economic consequences of trade (which will depend on the trade competitiveness of the region in which they live) when forming their attitudes towards globalization? Does trade competitiveness attract foreign direct investments? Do trade shocks (for example, a sudden surge in imports, which likely affects different regions differently) have an impact on elections? Do legislators consider the economic interests of their electoral districts when casting votes? Does trade competitiveness increase a region's economic growth rate?

The first step in our approach at measuring trade competitiveness is to calculate four different measures of revealed comparative advantage by industry at the national level using disaggregated trade data. In a second step, we then combine these national-level measures with employment data in subnational regions to arrive at measures of subnational trade competitiveness. In total, we present data for 1212 regions in 62 countries and all continents over a 21 year period. We offer each of the four measures at two different aggregation levels, once at the overall and once at the sector level. In terms of sectors, we distinguish between agriculture, mining, manufacturing, and services.

Our approach differs from existing attempts at measuring the competitiveness of territorial units in several important ways. For one, we calculate (trade) competitiveness without recourse to potential drivers of competitiveness. Basically all existing research measures territorial competitiveness relying on input factors such as the number of people with tertiary education or the presence of certain infrastructure. Instead, we try to directly capture the ability of firms from a subnational region to sell on world markets and to compete with imports. Doing so allows for an analysis of the extent to which different factors contribute to a region's trade competitiveness, which would be tautological when the drivers are part of the measure itself. In turn, since our measures heavily rely on trade data, we measure trade competitiveness rather than some overall economic competitiveness. Clearly, not all parts of an economy are exposed to international trade, even if indirectly trade matters for a larger part of the economy. Finally, we 
also measure trade competitiveness without concern for a region's wealth or income per capita. By definition, all countries - and not only highly developed countries - have a comparative advantage. As a result, in both more or less developed countries, regions can have an economic structure that is aligned with their country's comparative advantage. If trade competitiveness just captured income per capita, there would be no need for such a measure in the first place, as it would just duplicate measures such as Gross National Income.

We focus on trade competitiveness at the subnational level because a measure for the trade competitiveness of a country likely hides much variation across subnational entities. In the United States, for example, the economic structure of California is substantially different from the economic structure of Louisiana, meaning that the two also likely score differently with respect to trade competitiveness. These differences across subnational regions tend to be even more pronounced in emerging economies. What is more, for individuals the trade competitiveness of the region in which they live may be more important than the one of the country as a whole, as it may better reflect their economic reality. For example, a person living in a region with a high value on trade competitiveness may experience globalization very differently from one living in the same country but in a region with low trade competitiveness. This is illustrated by the fact that support for Brexit in the United Kingdom strongly varied across regions (Carreras, Irepoglu Carreras, and Bowler 2019).

Our study speaks to several strands of literature. Most directly, the paper is relevant for a large literature on territorial and especially regional competitiveness (Marsh and Tokarick 1996; Huggins et al. 2014; Kitson, Martin, and Tyler 2004). We add new measures of trade competitiveness to this strand of research that complement alternative approaches at measuring regional competitiveness. Moreover, trade competitiveness is key for understanding the political economy of trade (Baldwin 1996). For example, subnational trade competitiveness may be an explanatory factor in models explaining trade policy attitudes of individuals (Scheve and Slaughter 2001). Furthermore, for the large literature on the economic and political effects of globalization subnational trade competitiveness can serve as predictor, mediator, or dependent variable. For example, to which extent Greece's entry into the Euro zone affected its economic competitiveness is a pertinent question (Zemanek 2010). Our measures may show that the effects of the Euro on competitiveness differs across regions. 
In the following, we first conceptualise and define the concept of subnational trade competitiveness. Next, we discuss how we measure subnational trade competitiveness by combining four measures of revealed comparative advantage with region-level employment data. In a final part, we provide descriptive evidence, including short case studies of regions in South Korea and Bolivia, that shows the plausibility of the resulting measures of subnational trade competitiveness.

\section{Measuring subnational trade competitiveness}

\subsection{Conceptualizing subnational trade competitiveness}

Firm competitiveness refers to firms' ability to sell their goods and services on markets. That is, to be competitive, firms need to produce goods and services that meet consumer demand in the markets they target. Whether a firm is economically competitive matters strongly for its chances of survival in the market. If it is not competitive, it either goes bankrupt or requires government support to survive, for example in the form of subsidies or trade barriers that protect it from more competitive suppliers.

Transferring this logic to territorial units is not straightforward (Krugman 1996; Aiginger 2006). Most fundamentally, territorial entities do not sell any goods or services on the market; only firms do. Moreover, the survival of a country or any other territorial entity does not depend on its ability to compete on markets. And whereas a firm generally needs to make a surplus, any definition that equates territorial competitiveness with the ability to achieve a balance of trade surplus is correctly criticized as mercantilist.

Building on an intense debate over these issue (e.g. Krugman 1996; Budd and Hirmis 2004; Berger 2008), we thus conceive of subnational trade competitiveness as the extent to which a subnational region's economic structure is aligned with the comparative advantage of the country to which it belongs. By definition, each country has a comparative advantage in the production of some goods or the provision of some services. Comparative advantage results from differences in the opportunity costs of producing specific commodities across countries, which in turn are largely driven by different factor endowments. Countries that are capital-abundant generally have a comparative advantage in the production of capital-intensive goods and ser- 
vices; countries that are labour-abundant have a comparative advantage in the production of labour-intensive goods and services.

Rather than assuming countries' comparative advantage, we use trade data to establish their revealed comparative advantage. As doing so is not straightforward, we employ four different approaches at measuring revealed comparative advantage. We then establish to which extent a region's economy produces goods and services for which the country has a comparative advantage. Production generally is not equally distributed across a country because regions differ in natural advantages, infrastructure, and policies. Larger values on the resulting measure of subnational trade competitiveness mean that a region's economic structure is more aligned with the country's revealed comparative advantage; lower values that the region's economy is less well aligned with the country's revealed comparative advantage. What the values thus capture is the ability of a region's firms to exports the goods and services they produce on world markets relative to the ability of firms from other regions in the same country. Moreover, two of the four approaches that we introduce below also capture the ability of a region's firms to withstand international competition in domestic markets relative to firms in other regions.

The values that we get for these measures cannot be easily compared across countries. In some countries, we see much more variation across regions in terms of economic structure. This means that the values for the most trade competitive regions are higher and the values for the least trade competitive region are lower than in more homogenous countries. Nevertheless, the trade competitiveness values can be compared across regions within countries and for the same region over time. These kinds of variation are relevant for many important debates. In fact, subnational trade competitiveness as conceptualized here should both reflect and affect economic and political decisions. For example, foreign firms may be more likely to invest in regions with high values on trade competitiveness. Moreover, politicians and voters in these regions may be more supportive of free trade and globalization than in other parts of the country. In turn, shocks that lead to a decline in a region's trade competitiveness may lead to a decline in the public support that politicians in that entity enjoy. The often cited 'China shock' (Autor, Dorn, and Hanson 2016) is one prominent example of such shocks. There is no doubt, hence, that subnational trade competitiveness conceived of as a region's alignment with the country's overall comparative advantage is an important social science concept. 
Figure 1: Calculation of subnational trade competitiveness

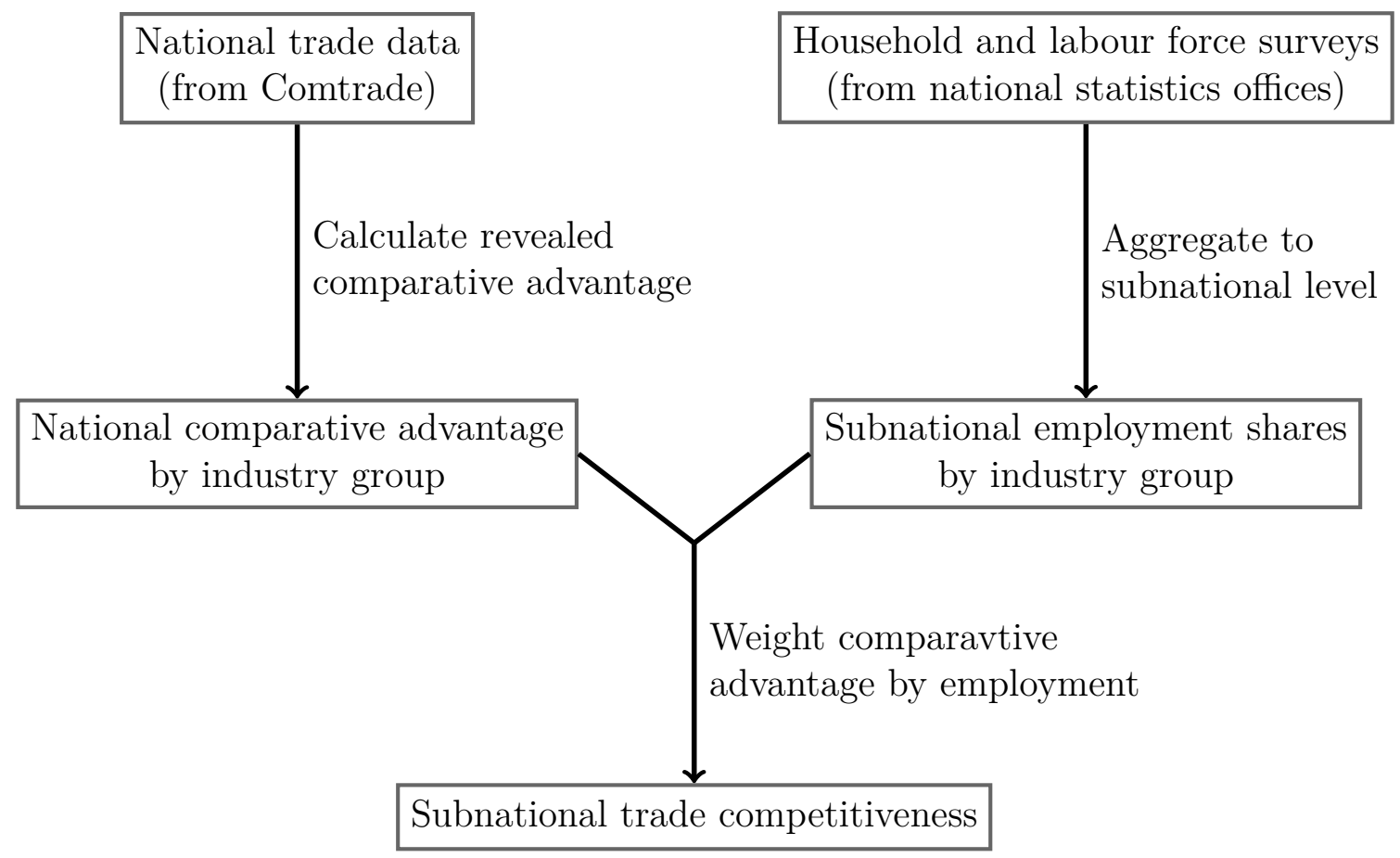

In the following, we discuss how we calculate our measures of subnational trade competitiveness. We do so in two steps: first, we calculate countries' revealed comparative advantage for specific industries; and then we weigh the resulting values at the industry-country level with region-level employment data to arrive at the values for subnational trade competitiveness. Figure 1 provides an illustration of our approach.

This approach rests on the key assumption that if there is a firm from a specific industry located in a specific region, its revealed comparative advantage is the same as that of another firm in the same industry in another region of the same country. This assumption is plausible because trade barriers are largely absent within countries, meaning that more competitive firms should displace less competitive firms in the same country. Of course, our assumption does not mean that there are not more and less competitive regions in a country; it just means that if there are factors that make an industry in a specific region of a country more competitive than in other regions (e.g. because of access to cheaper labour, infrastructure, or natural resources), this industry should concentrate in that region. 


\subsection{Measuring a country's (revealed) comparative advantage}

Establishing the industry-level comparative advantage of a large number of countries over time is no easy feat. Illustratively, there are simply no data available on the costs of production of different goods (and the provision of different services) for many countries at different times. As a result, Balassa (1965) proposed to use trade data to measure a country's "revealed comparative advantage" (RCA). Countries' trade data have the advantage that they are widely available and are harmonized in terms of product classifications. Concretely, Balassa suggested standardizing the share of a specific good in total exports of a country by the given product's share in world exports. In form of an equation:

$$
R C A_{c p t}=\frac{\frac{X_{c p t}}{X_{c t}}}{\frac{X_{p p t}}{X_{r t}}},
$$

where $X$ refers to exports, $c$ to the country, $p$ to the product, $t$ to the year, and $r$ to the reference countries (e.g. the rest of the world minus country $c$, which we use in this study). Values of $R C A_{c p t}$ above 1 indicate that a country has a comparative advantage in a given product, whereas values below 1 indicate that a country has a comparative disadvantage. This is a measure of revealed comparative advantage, as it takes actual trade data (which may be affected by government policies such as tariffs or subsidies) to infer comparative advantage.

Since the publication of Balassa's paper, many authors have suggested alternative ways of calculating revealed comparative advantage (for an overview, see Liu and Gao 2019). Among the many measures that have been proposed in this debate, we choose four, all of which have the advantage that they have explicit upper and lower bounds. In fact, all four measures below have a theoretical range from -1 (greatest comparative disadvantage) to +1 (greatest comparative advantage), with a value of 0 indicating that a country has neither a comparative advantage nor a comparative disadvantage in producing a certain good or service. The other measures that have been proposed are either very similar to at least one of the measures considered here or have been shown to have serious problems.

The first RCA measure that we use is a transformation of Balassa's original measure with the aim of making it symmetric around the neutral state of 0. Concretely, Laursen (2015) proposed the following symmetric RCA (RCA (symmetric)): 


$$
R C A(\text { symmetric })_{c p t}=\frac{R C A_{c p t}-1}{R C A_{c p t}+1}
$$

where the letters have the same meaning as in equation 1 above. While the fact that this measure is symmetric around 0 is a nice property of $R C A$ (symmetric), many of the criticisms raised against Balassa's original RCA also apply to this variant. In particular, this measure generally assigns higher than expected values for countries and products that only account for a small share of world exports.

The second RCA measure that we rely on is an additive version of Balassa's original measure that was proposed by Hoen and Oosterhaven (2006). This additive RCA (RCA (additive)) is calculated as follows:

$$
R C A(\text { additive })_{c p t}=\frac{X_{c p t}}{X_{c t}}-\frac{X_{r p t}}{X_{r t}}
$$

again with the same notation as used before. According to Hoen and Oosterhaven (2006), this RCA measure has the advantage that it has a more stable distribution than the original RCA. Moreover, they criticize the original measure for having a mean above 1, although 1 should indicate the neutral point on the Balassa index. Just as $R C A$ (symmetric), $R C A$ (additive) is symmetric around the neutral value of 0 . A weakness of this measure, however, is that it is biased against products that only account for a small share of exports. Larger sectors receive larger values, everything else equal. This makes this measure sensitive to the level of aggregation at which it is calculated.

Because a country's comparative advantage should be visible in both exports and imports, we also consider two RCA measures that take imports into account. Concretely, our third measure is a slight adaptation of an approach originally suggested by Vollrath (1991). Vollrath proposed subtracting a measure equivalent to the original RCA but calculated for imports (so simply substituting imports for exports in equation 1) from the original RCA. We adapt this approach by first applying the RCA transformation suggested by Laursen (2015) and shown in equation 2. In form of an equation, the resulting $R C A$ (net) is calculated as:

$$
R C A(\text { net })_{c p t}=\left(\frac{R X A_{c p t}-1}{R X A_{c p t}+1}-\frac{R M A_{c p t}-1}{R M A_{c p t}+1}\right) / 2,
$$


where $R X A$ refers to the RCA calculated in equation 1 and $R M A$ to the equivalent measure calculated for imports. We divide this measure by 2 to give it the same theoretical range as the other three measures have. While taking into account imports can be seen as a strength of this measure, it is at the same time also a weakness. A country may appear to have a comparative advantage for a product only because it imposes high trade barriers that strongly limit imports.

Finally, UNIDO (1982: 23) proposed to use trade balance (which is the difference between domestic production and consumption) as a share of total trade as a measure of a country's RCA. This RCA (trade balance) is calculated as follows:

$$
R C A(\text { tradebalance })_{c p t}=\frac{X_{c p t}-M_{c p t}}{X_{c p t}+M_{c p t}},
$$

where $\mathrm{X}$ are exports and $\mathrm{M}$ imports, with the subscripts denoting the same as above. Values larger than 0 and up to 1 on this measure indicate net exports; negative values (with the lowest possible value being -1) net imports. This intuitive interpretation is a key advantage of this measure. Moreover, Leamer (1984) provides a theoretical rationale for its use as a measure of comparative advantage, as trade balance directly reflects the relative factor endowment of a country. Just as $R C A$ (net), however, this measure may be strongly affected by trade barriers.

We calculate these four measures relying on data from the United Nation's Comtrade database for trade in goods (United Nations 2020) and the OECD-WTO's BaTIS database for trade in services (OECD 2021). The goods trade data are disaggregated at the six digit level of the Harmonised System (HS) in its 2012 version, which contains approximately 5,000 commodity groups. The employment data that we need to calculate subnational trade competitiveness, however, are generally available at the three-digit level of the International Standard Industrial Classification of All Economic Activities (ISIC) maintained by the United Nations (UNSD 2008). This level of detail is called 'industry groups' in ISIC jargon. Depending on the revision of ISIC (there have been three different revisions in the past decades), ISIC distinguishes between 159 and 238 distinct industry groups (e.g. beverages manufacturing). We use official correspondence tables between ISIC and HS to aggregate the goods trade data to this industry group level before calculating the four measures of revealed comparative advantage. The services trade data contains ten categories. However, we entirely focus on tradeable services, that is financial services, insurance services, and information services, thus reducing this 
number to three categories.

All of the four measures aim at capturing the same phenomenon, namely revealed comparative advantage. In fact, the correlation between them for the trade data we use is relatively high, with the partial exception of the RCA (additive). Their high correlation and the distinct strengths and weaknesses of the measures mean that we cannot say that one consistently outperforms the others. Rather, which measure works best likely depends on the question they are used to address.

\subsection{Calculating subnational trade competitiveness}

To move from the industry-country level data on revealed comparative advantage to a measure of subnational trade competitiveness, we combine them with employment data in subnational regions that allow us to understand where certain industries are located. Concretely, we weight a country's revealed comparative advantage in a specific industry with the number of workers who are employed in this industry in a specific region.

Nearly all countries regularly (quarterly, annually or multi-annually) conduct representative household or labour force surveys that include a question about the main job of the respondent. In countries where these surveys are not available, we used regular census surveys, which are conducted in five- or ten-year intervals and include the same question. As mentioned above, this employment information is generally coded according to the ISIC scheme. In those countries that use their own adaptations of ISIC or have developed unique coding schemes, we use official correspondence tables to transfer this data into an applicable ISIC revision. Additionally, the level of detail varies between surveys: some countries report very specific industries (coded with four or more digits) whilst others only report very broad industry sectors (coded with only two digits). To ensure both comparability and validity, we toss out all surveys that use only two digits and reduce all other data to three digits. ${ }^{1}$

We then multiply each workers' survey weight with the revealed comparative advantage data for the industry in which the worker is employed. Finally, we sum up all the products between worker weights and respective RCA values to arrive at our measures of subnational

\footnotetext{
${ }^{1}$ We also exclude regions with fewer than 50 respondents across all tradable sectors because estimates are increasingly unreliable and unstable in smaller samples. In such cases, individual respondents are too influential and changes in competitiveness may simply reflect a marginally different composition of the sample.
} 
trade competitiveness. In summing, we aggregate both to the sector-region level (distinguishing four sectors, namely agriculture, mining, manufacturing, and services) and to the overall region level. In form of an equation:

$$
S T C_{s t}=\sum_{p=1}^{N}\left(R C A_{c p t} * E S_{p s t}\right),
$$

where $S T C_{s t}$ is the subnational trade competitiveness value for subnational region $s$ at time $t$ (or a region-sector), $p$ is the industry group, $R C A_{c p t}$ is the value of the specific RCA index (one of equations 2-5) for industry group $p$ in country $c$ at time $t$, and $E S_{p s t}$ is the employment share in the industry group and region in year $t$.

Given that we have four different ways of calculating RCA (symmetric, additive, net, and trade balance), and that we aggregate these measures to both the region as a whole and the region-sector level (agriculture, manufacturing, mining, and services), we end up with 20 different measures for each region and year. Illustratively, we arrive at values for subnational trade competitiveness based on the symmetric RCA for a region as a whole (STC (symmetric) OV) or based on the net RCA for the services sector $\left.(S T C \text { (net) })_{S E}\right)$. To make their interpretation more intuitive, but without this changing them per se, we subtract the national mean of the respective overall subnational trade competitiveness measure from all measures. Positive values then indicate that a region is more oriented towards the country's comparative advantage than the average region. ${ }^{2}$

Compared to alternative weights that might be used to aggregate the industry-country RCA data to the subnational level, such as company profits or output, employment data has two crucial advantages. First, the necessary data can be obtained from household and labour force surveys, which are available for a large number of countries in a standardized way. Second, weighting based on employment has conceptional benefits for many applications of this measure in the social sciences that might focus on voting behaviour, political attitudes, or any broader social developments that account for the material situation of people.

Generally, we follow the ISO 3166-2 standard for determining the regions to which we aggregate. In most countries, the ISO 3166-2 standard reflects the first-level administrative

\footnotetext{
${ }^{2}$ This means that a dichotomous version of our measures (positive or not) can be compared across countries. The absolute values of the measures, however, are not necessarily comparable across countries. When using the absolute values in cross-national research, we thus strongly recommend using country fixed effects.
} 
divisions of the country. These might be states (e.g. in Brazil, Germany, India, Mexico, and the USA), provinces (e.g. in Argentina, Belgium, Ecuador, and South Africa), or regions (e.g. in Ghana, Namibia, Peru, and Slovakia). However, in some countries, the ISO 3166-2 standard is too detailed for our purposes, which would reduce the number of survey respondents per regions to an unreliably low number. For example, this applies to the counties of Estonia, the departments of France, and the municipalities of the United Kingdom. In these cases, we aggregate to larger statistical regions based on the European Nomenclature of Territorial Units for Statistics (NUTS). Our approach is very flexible in this regard: we could easily calculate the trade competitiveness of larger subdivisions or groupings of regions (such as the nine Census Divisions in the USA instead of the 50 states plus Washington, DC) or that of smaller subdivisions (such as the 107 provinces of Italy instead of its 21 NUTS 2 regions).

The number of regions per country varies from six in Estonia and Rwanda to 81 in the Philippines. The median country has 16 regions. (See Table A1 in the Appendix for more information). In terms of population, the smallest region is Embera Wounaan in Panama with about 12,000 inhabitants, whereas the largest region is Uttar Pradesh in India with nearly 200 million inhabitants. The median region in the sample has about 2 million inhabitants.

We have data for a total of 1,212 regions in 62 countries over a 21 year period (19992019). Some of these years have been extra- or interpolated by carrying the employment data backwards and forwards. However, we always use the respective trade data for a year. In other words, even if we impute the distribution of employees in an industry in a year, we use the correct trade data for this year. Figure 2 shows for which country-years we needed to extraor interpolate data. Our dataset contains labour surveys for dark purple fields. The brighter the field, the larger the distance to the last labour survey. Belgium (BEL) illustrates this neatly. The Belgian Statistical Office only provides labour surveys in sufficient quality since 2013. Thus, the competitiveness estimate for 2010 uses the 2010 trade data and merges it with the first observation carried backwards, that is the 2013 employment data. For countries like Germany (DEU), we obtained data every three years. The 2016 employment data is thus a linear approximation from 2015 to 2018. Again, we use the 2016 trade data. Our sample of countries represents all areas of the world. For example, we are able to capture subnational trade competitiveness for large parts of the Americas and Europe, but also for several African, 
Figure 2: Data availability

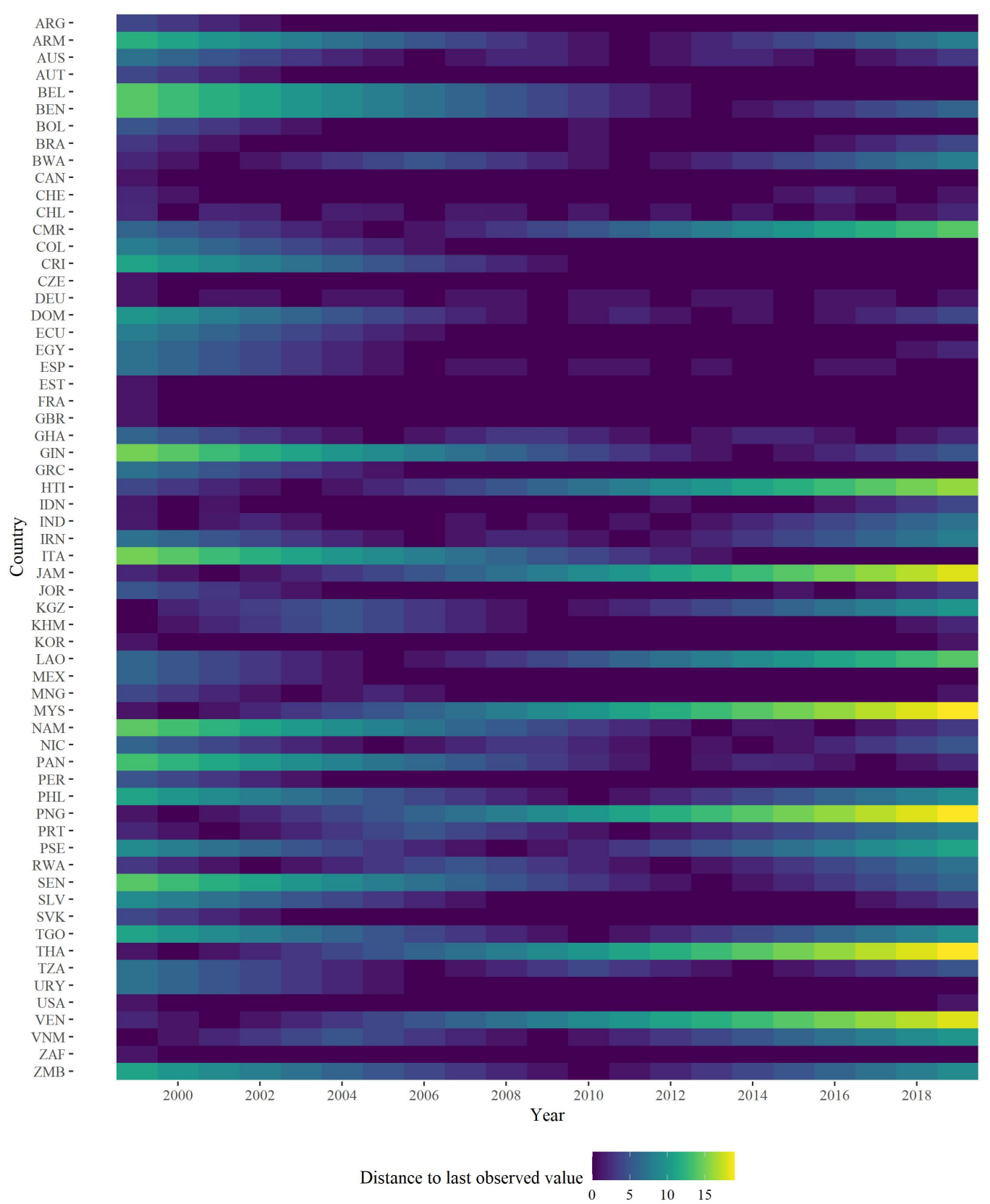

Asian and Arab countries.

\section{Illustrating the plausibility of the measures}

In this section, we first show that the various measures of subnational trade competitiveness (for the region overall) are highly positively correlated with each other and discuss to which extent subnational trade competitiveness varies within countries. Second, we provide several tests of the data's face validity. Finally, we provide two brief case studies of South Korea and Bolivia that help better understand the dynamics. Further analysis of the data for all measures, 
regions, years, and sectors is possible via the following Shiny app:

https://subnationaltradecompetitiveness.shinyapps.io/Comp_Shiny/.

\subsection{Descriptive evidence}

We first present correlations between the measures of subnational trade competitiveness (as calculated for the region as a whole). The results suggest that all measures, with the partial exception of STC (additive) $O V$, are highly correlated. Particularly the measures based on the net and trade balance approaches behave very similarly. In fact, the correlations between STC (symmetric) OV $S T C$ (net) $_{O V}$, and STC (trade balance) OV are all above 0.82 (also see Figure A7 in the Appendix). The reason why STC (additive) OV differs a bit more from the other measures may be that it systematically punishes small sectors, whereas the other measures potentially punish larger sectors. Nonetheless, the three correlations with STC (additive) OV are all above 0.46, indicating that all measure tap into the same latent concept (that is subnational trade competitiveness).

Next we analyse to which extent subnational trade competitiveness varies within countries. Figure 3 shows the ranges across regions within each country. In other words, each bar shows the difference in subnational trade competitiveness between the region with the lowest and the region with the highest value on subnational trade competitiveness in a country. The colours indicate the different measures. The horizontal, dashed lines indicate the average range across all countries in our sample.

The figure shows that the within country variation that we find is substantial. All variables theoretically range from $\pm 2{ }^{3}$ Against this theoretical range of 4 , the within country range is large. For example, the mean range for the STC (symmetric) OV measure is around 0.8; and hence about 20 percent of the maximum possible range. We find similar variation for the STC (net) OV and STC (tradebalance) OV measures. Only the STC (additive) OV operates on a more restricted part of the theoretical range.

Zooming in to individual countries, across all measures we find that the countries with relatively little heterogeneity tend to be highly developed, whereas the lower income countries tend to exhibit more variation across regions. Austrian and German federal districts, for example,

\footnotetext{
${ }^{3}$ They are standardised between \pm 1 . Since we subtract the country mean, theoretically it could take values in the range \pm 2 .
} 
Figure 3: Within-country range of subnational trade competitiveness

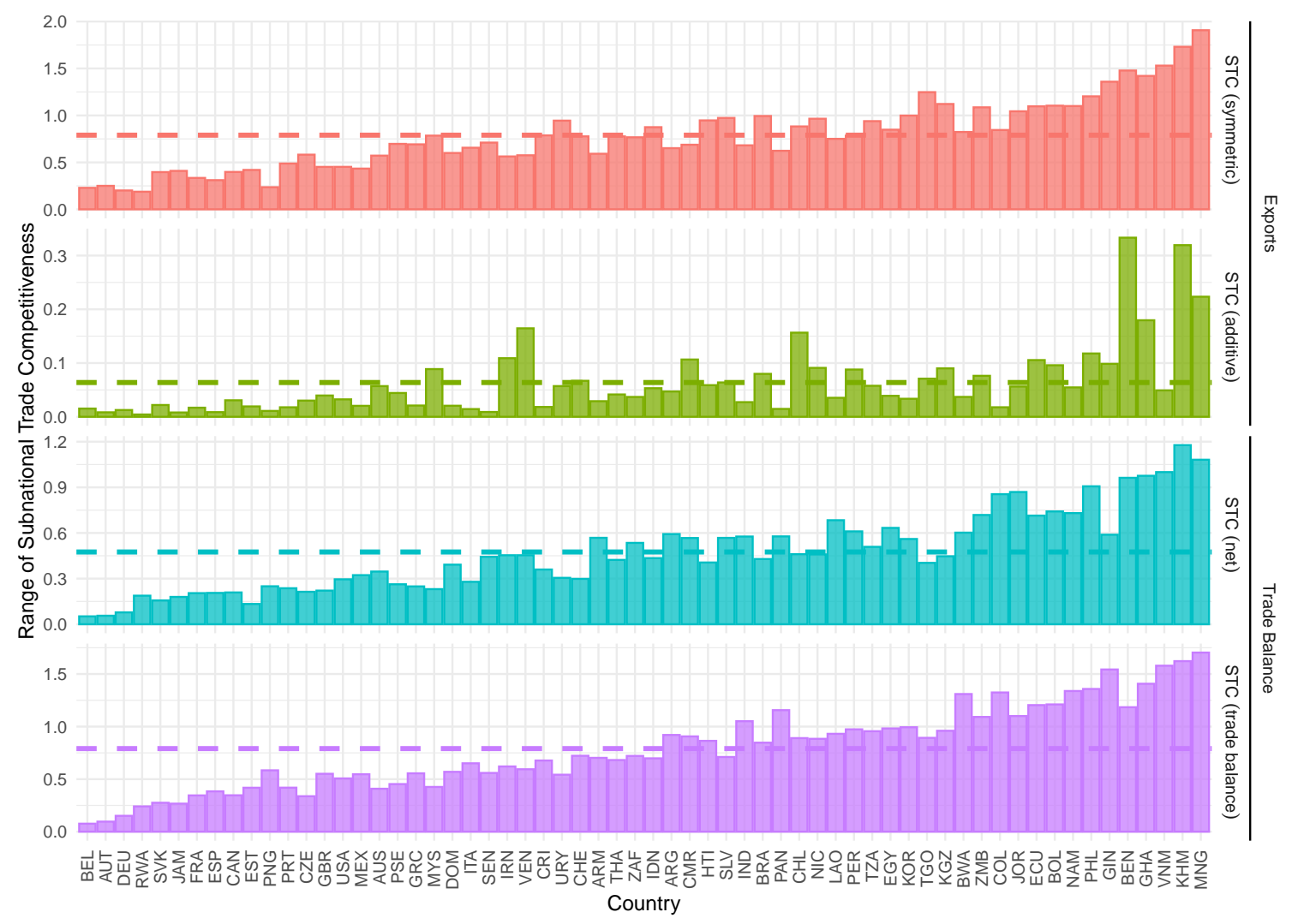

Note: Bars are sorted by the sum of ranges across all measures.

are similar in their employment structure, thus their level of within-country variation is rather small. On the other end of the extreme, we observe lower income countries that tend to have one political and economic center and several more rural regions. A country such as Argentina that has several highly industrialised (e.g. Buenos Aires) and other more rural regions (e.g. La Pampa and Tierra del Fuego) is placed somewhere in the middle of the distribution. Again, the additive measure (STC (additive) OV) behaves slightly different from the other measures, as it produces some extreme outliers (Benin and Cambodia have five times the average range). Nevertheless, even for this measure we find the difference between more and less highly developed countries discussed before.

\subsection{Relationship between competitiveness and GNI}

Since by definition all countries have a comparative advantage in the production of some goods or the provision of some services, we should see regions with relatively high and regions with relatively low values on subnational trade competitiveness in each country. As a result, our 
measures cannot simply reflect cross-country differences in levels of development. Nevertheless, at the subnational level, trade competitiveness and level of development may correlate. It could be that within countries, the regions with the highest level of development also receive the highest scores on subnational trade competitiveness. If so, our measures could simply be substituted with a measure of regional GDP per capita.

As outlined in the introduction, there are theoretical reasons to believe this is not the case. Nevertheless, in this subsection we analyze this correlation empirically. Figure 4 shows correlations between region's trade competitiveness and Gross National Income per capita by country. Bars (which indicate the correlation) are sorted by the countries' average GNI per capita over our 21-year observational period. The correlations between the two variables vary widely from quite negative to quite positive, which demonstrates that they measure different attributes of these regions. In Guinea, for example, three of four measures have a negative correlation with GNI per capita of -0.85 or below. In contrast, in Great Britain all four measures show a correlation of 0.84 or higher.

Nevertheless, we observe at least a weak pattern, as indicated by the black line that summarizes the correlations via a LOESS regression. The correlation is on average positive for the more developed countries in the sample and negative for the less developed countries. This suggests that in less developed countries, poorer subnational entities are more focused on the comparative advantage of the country, which might be explained by lower production costs (mainly wages) in these regions. In more developed countries the relationship is reversed and richer regions are more in line with the comparative advantage of the country. This might be a result of the availability of high skilled workers in wealthy districts. Overall this pattern suggests that the underlying factors that determine whether a region is oriented towards a country's comparative advantage or not are different at different levels of development. 
Figure 4: Correlation between regional GNI per capita and subnational trade competitiveness

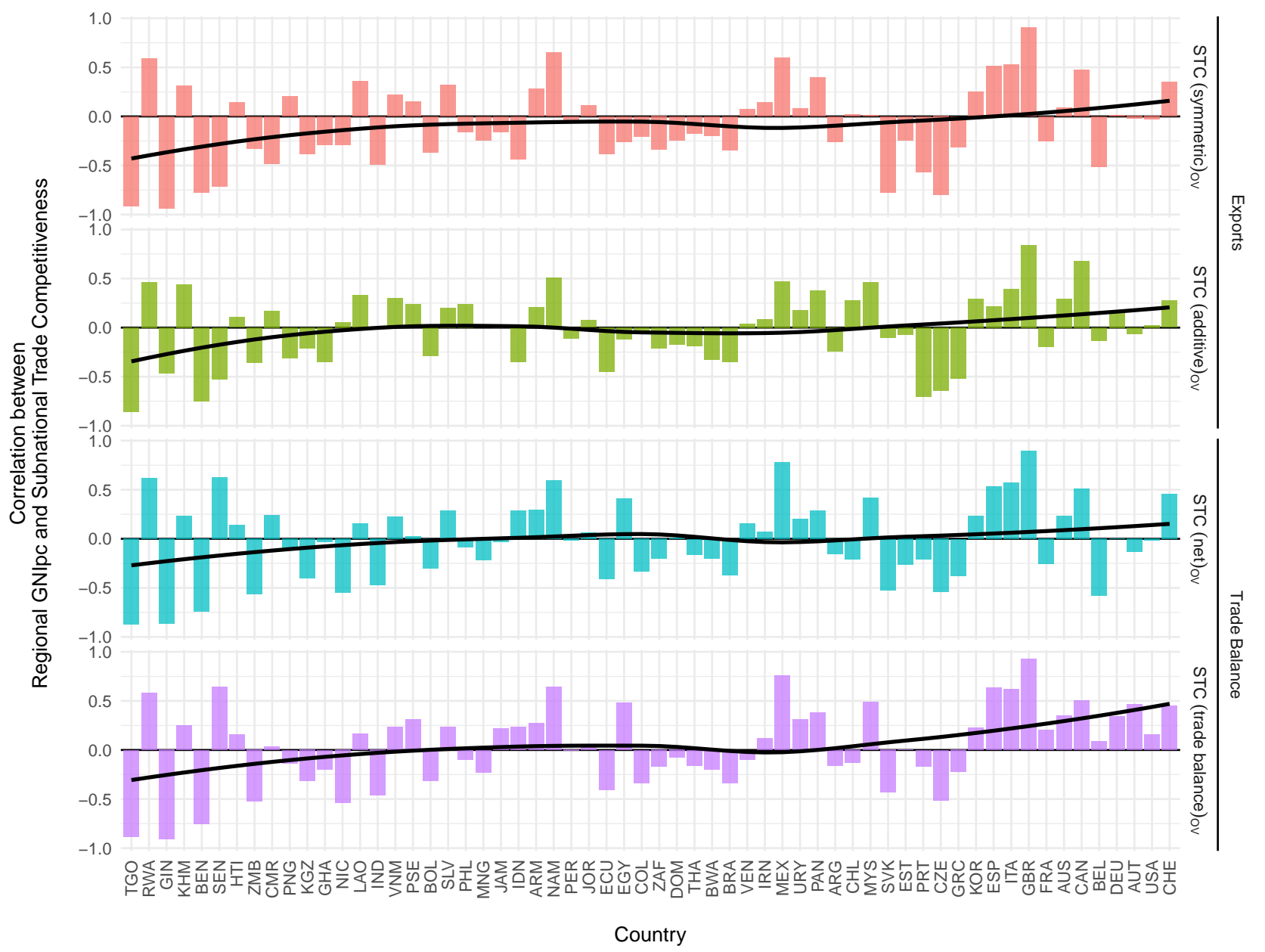

Note: Bars are sorted by country GNI per capita.

\subsection{Case studies: South Korea and Bolivia}

We conclude our empirical investigation by providing two brief case studies of South Korea and Bolivia. These two cases, chosen to include a more developed and a less developed country, allow us to convey the intuition behind our measures.

\subsubsection{South Korea}

South Korea has a mix of highly industrialized and rural regions. On the one hand, some regions are home to a large electronics industry led by Samsung and LG. In addition, they host the Hyundai Kia Automotive Group, which is one of the world's largest automobile producers. Hyundai Heavy Industries, Samsung Heavy Industries, and others also account for a large share of global shipbuilding. ${ }^{4}$ These regions should score highly on subnational trade competitiveness,

\footnotetext{
${ }^{4}$ https://www.statista.com/statistics/263895/shipbuilding-nations-worldwide-by-cgt/.
} 
as their economies are in line with South Korea's comparative advantage. On the other hand, some regions are mainly characterized by agricultural production. These regions should get low values on our measures, as overall South Korea is not particularly competitive in agriculture.

Indeed, we find considerable variation in trade competitiveness across regions. In Figure 5, the city-province of Ulsan (circle with plus) consistently scores highest on trade competitiveness, across all four measures. Ulsan is home to one of the most important harbours in South Korea. It also hosts the Uslan industrial zone in which Hyundai has its headquarters and most of its production. Hence, it is clearly oriented towards South Korea's comparative advantage in manufacturing. In fact, almost a third of all employees in Ulsan work in the manufacturing sector. Another region that scores highly on subnational trade competitiveness is Gyeongsangnam-do (South Gyeongsang; purple star). This region's economy is characterized by large shipbuilding and chemical industries. Again, these are industries that form part of South Korea's comparative advantage.

The country's capital, Seoul, used to be South Korea's industrial centre after World War II. Decentralisation, however, lead to substantial relocation of industry to other regions. Thus, while large corporations continue to have their headquarters in the capital, their production moved to other provinces. Not surprisingly, Seoul does not score very high on subnational trade competitiveness, taking a place in the middle to lower end of the distribution. The region that consistently scores lowest (North Jeolla), finally, has a relatively small manufacturing sector. In combination with the relatively large agricultural sector, which is rather uncompetitive in South Korea, this means that North Jeolla's economy is not in line with the country's comparative advantage. Figure A8 in the Appendix provides more detailed evidence on these four regions that is further indication of the plausibility of our measures. 
Figure 5: Subnational trade competitiveness of South Korean regions over time

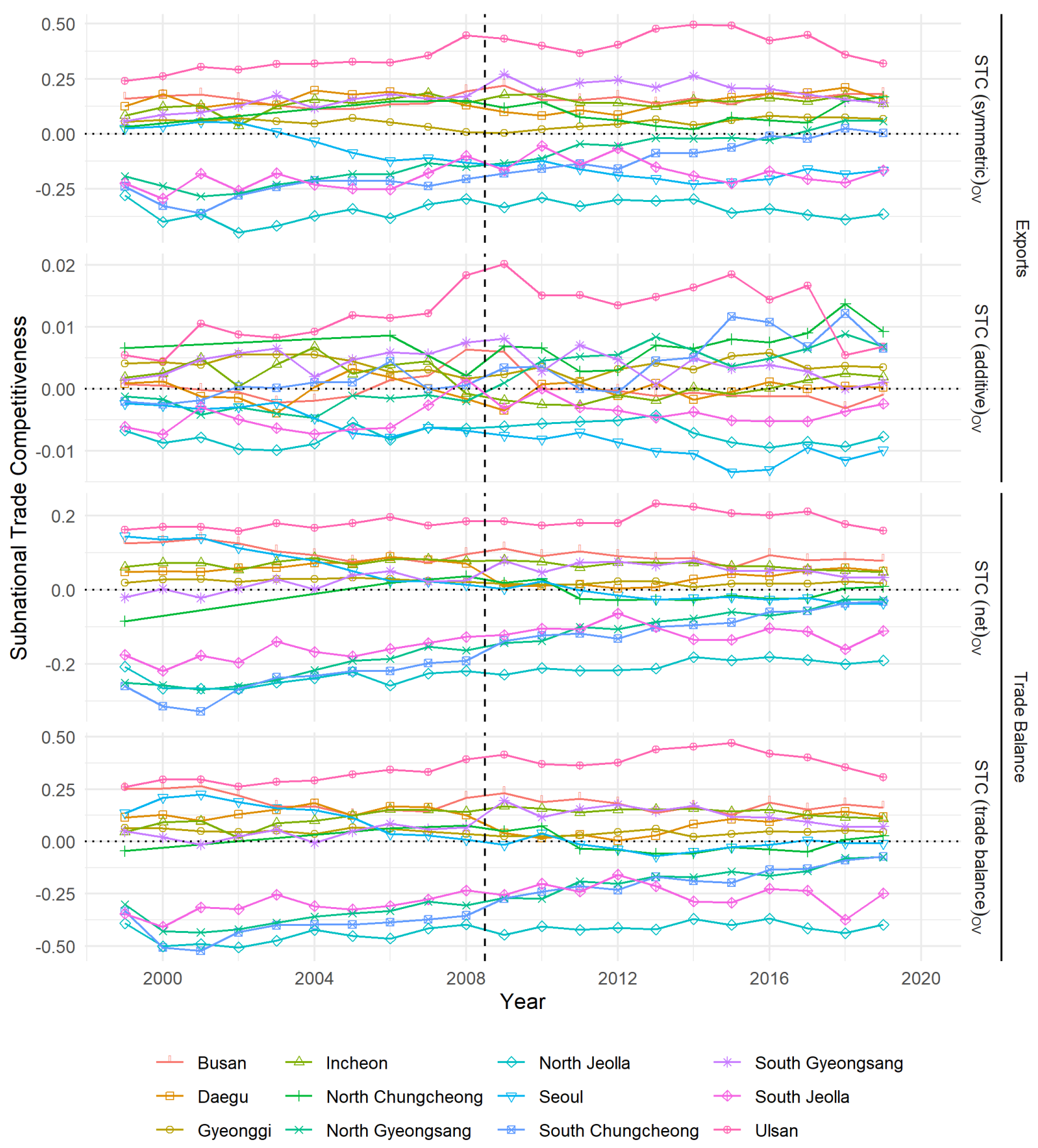

Note: The dashed line between years 2008 and 2009 represents a change in ISIC coding scheme from ISIC rev 3 to ISIC rev 4. 


\subsubsection{Bolivia}

In the second case study, we look at Bolivia. Bolivia's comparative advantage lies in agriculture and the mining of silver. We thus expect regions with silver mines and strong agricultural production to score highly on subnational trade competitiveness. Regions with a strong manufacturing sector, by contrast, should receive low values on subnational trade competitiveness.

In fact, this is what we find (see Figure 6). The region of Potosí is not only Bolivia's mining centre, as it contains the world's largest silver deposits. It also has a large agricultural sector. Overall, therefore, Potosí's economy is focused on the country's comparative advantage. It is no wonder then that this region scores highly on subnational trade competitiveness across all four measures.

Figure 6: Sectoral subnational trade competitiveness in Bolivia (2018)

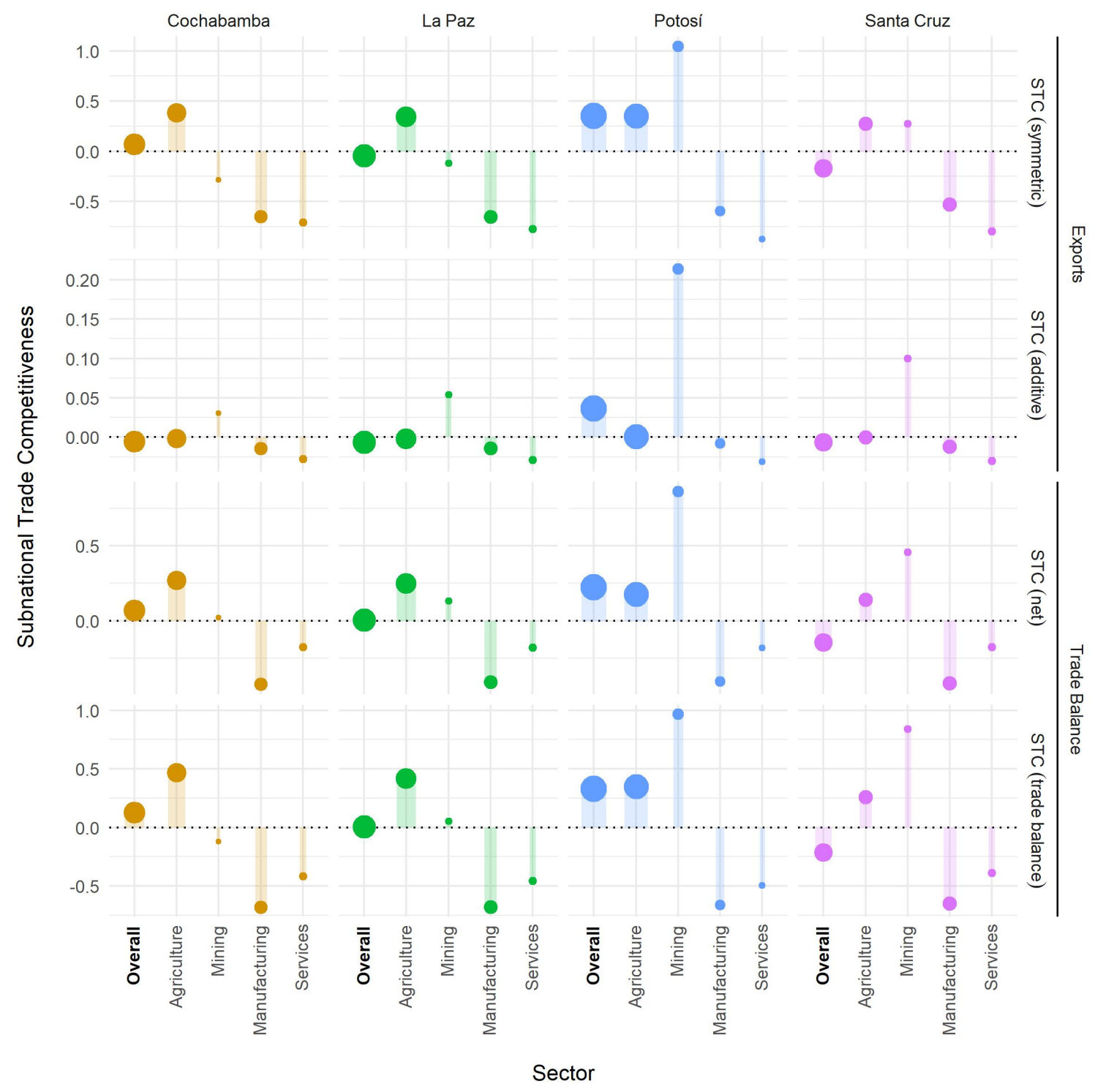


In contrast, La Paz has a quite different economic structure. It also has a relatively large agricultural sector, but a substantial part of employment is engaged in manufacturing. Moreover, the mining sector in La Paz is not only smaller than the one in Potosí, but also does not focus on the mining of silver. In La Paz, 60 percent of employees in the mining sector are in the ISIC rev. 4 group 081 'Quarrying of stone, sand and clay'. The RCA values for this industry group indicate that it is not part of Bolivia's comparative advantage. Overall, therefore, we find that La Paz's subnational trade competitiveness is only average. The same applies to the region of Cochabamba, which is the industrial hub of Bolivia. Of the four regions shown in Figure 6, Santa Cruz scores lowest on subnational trade competitiveness, as it has the largest manufacturing sector, in combination with a smaller agricultural sector and only very limited mining activity.

While this between-region variation is interesting, we also observe variation over time. For this, we focus on one of the most competitive regions, Oruro (see Figure 7). Similar to Potosí, this region has traditionally been characterized by highly competitive mining. From 2004 to 2008, however, we observe a decline in its overall subnational trade competitiveness (see first dots for each year). As illustrated by the estimates for each year, while the competitiveness of individual sectors hardly changed, the region's employment structure changed substantially. The percentage of employees working in mining decreased from more than 11.6 percent in 2004 to 2.9 percent four years later. To some extent, this can be explained by debates about the ownership of different mines, resulting in protests and eventually the closing of some mines. ${ }^{5}$ Thus, while mining remains fairly competitive, Oruro's mining sector shrunk and as a result its overall trade competitiveness decreased.

${ }^{5}$ https://www.internationaltin.org/confrontation-at-huanuni-mine-escalates/. 
Figure 7: Sectoral subnational trade competitiveness in Oruro over time

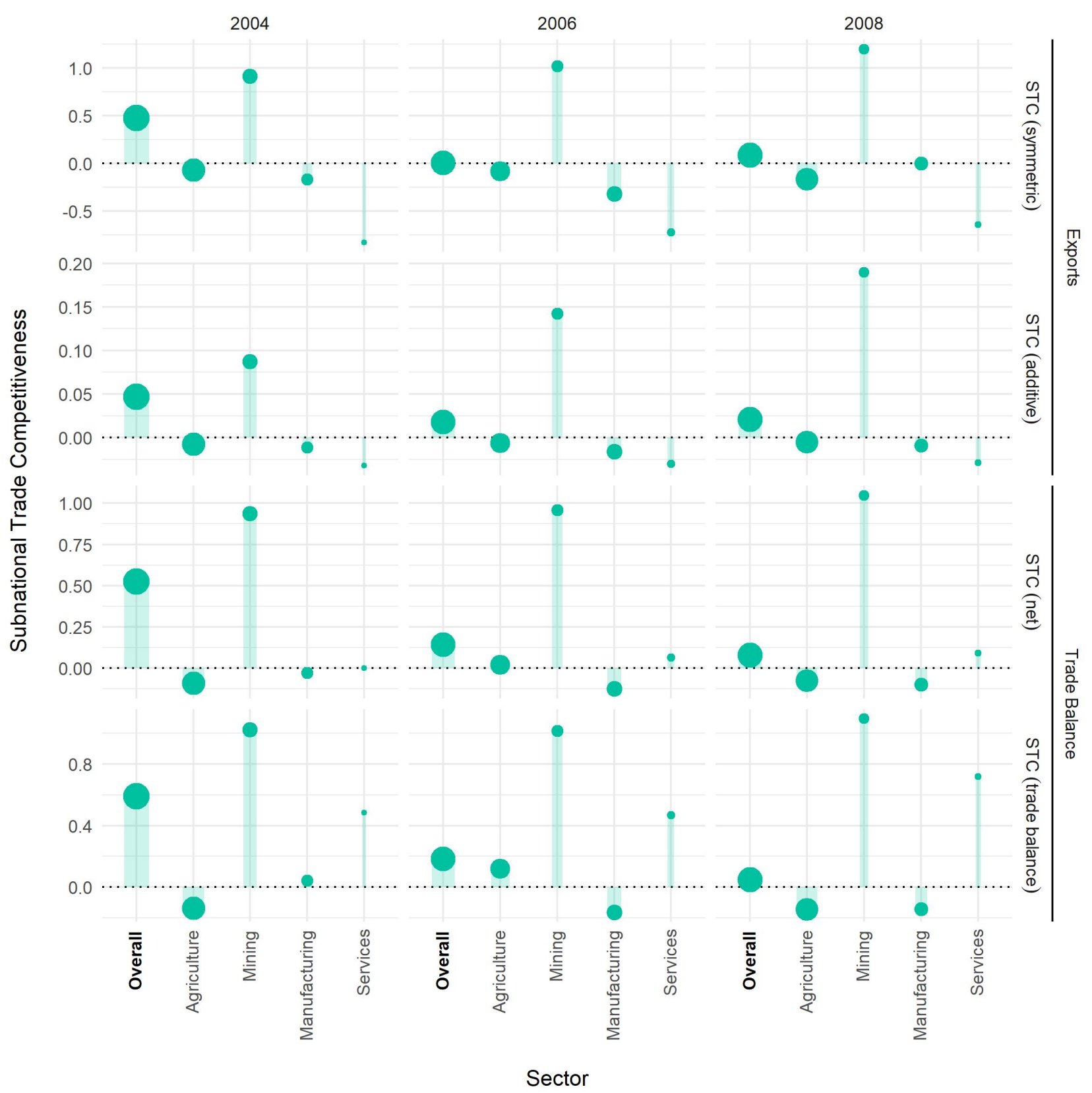

\section{Conclusion}

We have presented new measures of subnational economic competitiveness. Descriptive evidence on these measures suggests that they plausibly capture regions' orientation towards the country's comparative advantage. Moreover, this evidence has provided a rationale for our effort in that it reveals much variation in subnational trade competitiveness within countries, which is largely independent of the region's level of development.

We expect that these data are useful for scholarly inquiries across various social science disciplines. For one, it would be interesting to investigate whether changes in subnational trade 
competitiveness matter for election outcomes. Do voters punish incumbents when the trade competitiveness of a region declines? Data on subnational trade competitiveness may also help better understand public opinion towards globalization. The economic effects of globalization should be quite different in regions that score high on trade competitiveness than in regions that score low on trade competitiveness. Moreover, using our measures as dependent variable, it would be interesting to study how (economic) policies affect subnational trade competitiveness. Our measures of subnational trade competitiveness could also allow new insights for research on foreign direct investments. Do multinational companies prefer to invest in regions with high trade competitiveness? Alternatively, does an inflow of foreign investments lead to an improvement in a region's trade competitiveness? Finally, for economic geographers, it might be interesting to investigate to which extent physical characteristics of regions correlate with trade competitiveness, especially also at the sectoral level. Overall, we are confident that our dataset will prove useful for a large number of researchers.

In future research, it would be interesting to improve our dataset in various ways. For one, it would of course be good to have data beyond the 62 countries included in this first version of the dataset. Unfortunately, for many countries it is very difficult to get a hold of household or labour surveys. Partly, this has to do with data protection laws that make it impossible for statistical offices to release the kind of disaggregated data we need here. Partly, it is also simply difficult to interact with statistical offices in some countries. In addition, and this could also be a partial solution to the issue just mentioned, it would be interesting to calculate our measures of subnational trade competitiveness not with employment data but with production data. Some countries indeed provide data on the share of gross regional income contributed by different industries. Alternatively, it may be possible to approximate these shares using firmlevel data. At least for some countries, such firm-level data may even allow for a calculation of our measures at an even more fine-grained level than the industry groups used here. Linking our data with firm-level data would anyhow be a worthwhile undertaking. In short, while already in their present format our data should be highly useful, future research could push this research agenda even further. 


\section{References}

Aiginger, Karl. 2006. "Competitiveness: From a Dangerous Obsession to a Welfare Creating Ability with Positive Externalities." Journal of Industry, Competition and Trade 6 (2): $161-177$.

Annoni, Paola, and Lewis Dijkstra. 2019. The European Regional Competitiveness Index 2019. Brussels: European Commission.

Autor, David H., David Dorn, and Gordon H. Hanson. 2016. "The China Shock: Learning from Labor-Market Adjustment to Large Changes in Trade." Annual Review of Economics 8 (1): 205-240.

Balassa, Bela. 1965. "Trade Liberalisation and "Revealed" Comparative Advantage." The Manchester School 33 (2): 99-123.

Baldwin, Robert E. 1996. "The Political Economy of Trade Policy: Integrating the Perspectives of Economists and Political Scientists." In The Political Economy of Trade Policy: Papers in Honor of Jagdish Bhagwati, ed. Robert C. Feenstra, Gene M. Grossman, and Douglas A. Irwin. Cambridge: MIT Press pp. 147-73.

Berger, Thomas. 2008. "Concepts of National Competitiveness." Journal of international Business and Economy 9 (1): 91-111.

Berger, Thomas, and Gillian Bristow. 2009. "Competitiveness and the Benchmarking of Nations-A Critical Reflection." International Advances in Economic Research 15 (4): 378-392.

Birnie, Esmond, Richard Johnston, Laura Heery, and Elaine Ramsey. 2019. "A Critical Review of Competitiveness Measurement in Northern Ireland." Regional Studies 53 (10): 1494-1504.

Budd, Leslie, and Amer Hirmis. 2004. "Conceptual Framework for Regional Competitiveness." Regional Studies 38 (9): 1015-1028.

Carreras, Miguel, Yasemin Irepoglu Carreras, and Shaun Bowler. 2019. "Long-Term Economic Distress, Cultural Backlash, and Support for Brexit." Comparative Political Studies 52 (9): 1396-1424.

Hoen, Alex R., and Jan Oosterhaven. 2006. "On the Measurement of Comparative Advantage." The Annals of Regional Science 40 (3): 677-691.

Huggins, Robert, Hiro Izushi, Daniel Prokop, and Piers Thompson. 2014. The Global Competitiveness of Regions. Abingdon: Routledge.

Huggins, Robert, Piers Thompson, and Daniel Prokop. 2019. UK Competitiveness Index 2019.

ILO, International Labour Organization. 2020. "Employment by sex and economic activity ILO modelled estimates, Nov. 2020 (thousands) - Annual.".

URL: $\quad$ https://www.ilo.org/shinyapps/bulkexplorer11/?lang=enEsegment=indicatorGid $=E M P \_2 E M P \_S E X \_E C O \_N B \_A$

Kitson, Michael, Ron Martin, and Peter Tyler. 2004. "Regional Competitiveness: An Elusive yet Key Concept?" Regional Studies 38 (9): 991-999.

Krugman, Paul. 1994. "Competitiveness: A Dangerous Obsession." Foreign Affairs 73 (2): $28-44$. 
Krugman, Paul R. 1996. "Making Sense of the Competitiveness Debate." Oxford review of economic policy 12 (3): 17-25.

Laursen, Keld. 2015. "Revealed Comparative Advantage and the Alternatives as Measures of International Specialization." Eurasian Business Review 5 (1): 99-115.

Leamer, Edward E. 1984. Sources of International Comparative Advantage: Theory and Evidence. Boston: MIT Press.

Liu, Bin, and Jianbo Gao. 2019. "Understanding the Non-Gaussian Distribution of Revealed Comparative Advantage Index and Its Alternatives." International Economics 158: 1-11.

Marsh, Ian W., and Stephen P. Tokarick. 1996. "An Assessment of Three Measures of Competitiveness." Weltwirtschaftliches Archiv 132 (4): 700-722.

OECD. 2021. "OECD Balanced Trade Statistics." https://www.oecd.org/sdd/its/balancedtrade-statistics.htm.

Porter, M. E. 1990. The Competitive Advantage of Nations. New York: Macmillan.

Scheve, Kenneth, and Matthew Slaughter. 2001. "What Determines Individual Trade-Policy Preferences?" Journal of International Economics 54 (2): 267-92.

Schwab, Klaus. 2019. The Global Competitiveness Report 2019. Geneva: World Economic Forum.

Smits, Jeroen, and Iñaki Permanyer. 2019. "The Subnational Human Development Database." Scientific Data 6 (1): 190038.

UNIDO. 1982. Changing Patterns of Trade in World Industry: An Empirical Study on Revealed Comparative Advantage. New York: UNIDO.

United Nations. 2020. "UN Comtrade Database.".

UNSD, United Nations Statistics Division. 2008. "International Standard Industrial Classification of All Economic Activities (ISIC), Rev.4.".

URL: https://unstats.un.org/unsd/publication/SeriesM/seriesm_4rev4e.pdf

Vollrath, Thomas L. 1991. "A Theoretical Evaluation of Alternative Trade Intensity Measures of Revealed Comparative Advantage." Weltwirtschaftliches Archiv 127 (2): 265-280.

Zemanek, Holger. 2010. "Competitiveness Within the Euro Area: The Problem That Still Needs to Be Solved." Economic Affairs 30 (3): 42-47. 


\section{Appendix}

\subsection{Available countries and years}

\begin{tabular}{|c|c|c|c|c|c|}
\hline Country & Years & Regions & Coding scheme & Survey type & Source \\
\hline Argentina & 17 & 24 provinces and districts & CAES & Household & INDEC (2021) \\
\hline Armenia & 1 & 11 regions and cities & ISIC adapted & Census & NSS (2011) \\
\hline Australia & 3 & 8 states and territories & ANZSIC & Census & ABS (2021) \\
\hline Austria & 17 & 9 states & NACE adapted & Household & StatAustria (2020) \\
\hline Belgium & 7 & 11 provinces and districts & NACE & Labor & StatBel (2020) \\
\hline Benin & 1 & 12 departments & ISIC adapted & Census & INSAE (2013) \\
\hline Bolivia & 15 & 9 departments & ISIC & Household & INE $(2021 a)$ \\
\hline Botswana & 2 & 10 districts & ISIC adapted & Census & StatsBots (2011) \\
\hline Brazil & 13 & 27 states and districts & CNAE & Household & IBGE (2021) \\
\hline Cambodia & 10 & 25 provinces and cities & ISIC & Household & NIS (2020) \\
\hline Cameroon & 1 & 10 regions & national & Census & BUCREP (2005) \\
\hline Canada & 20 & 10 provinces & NAICS & Labor & StatsCAN (2021) \\
\hline Chile & 8 & 16 regions & ISIC & Household & MDSF (2021) \\
\hline Colombia & 13 & 24 departments and districts & ISIC adapted & Household & DANE (2021) \\
\hline Costa Rica & 10 & 6 socioeconomic regions & ISIC & Labor & INEC $(2021 a)$ \\
\hline Czechia & 20 & 14 regions and districts & NACE & Labor & CSO (2021) \\
\hline Dominican Republic & 3 & 10 regions & ISIC & Household & ONE (2021) \\
\hline Ecuador & 13 & 24 provinces & ISIC & Labor & INEC $(2021 b)$ \\
\hline Egypt & 12 & 29 governorates & ISIC & Labor & CAPMAS (2017) \\
\hline El Salvador & 9 & 14 departments & ISIC & Household & DIGESTYC (2021) \\
\hline Estonia & 20 & 5 NUTS-3 regions & NACE & Labor & StatEst (2020) \\
\hline France & 20 & 26 NUTS-2 regions & NACE & Labor & INSEE (2020) \\
\hline Germany & 7 & 16 states & NACE & Household & DESTATIS (2020) \\
\hline Ghana & 3 & 10 regions & ISIC & Household & GSS (2021) \\
\hline Greece & 2 & 13 regions & NACE adapted & Census & ELSTAT (2021) \\
\hline Guinea & 1 & 8 regions and governorates & ISIC adapted & Census & INS (2014) \\
\hline Haiti & 1 & 10 departments & ISIC & Census & IHSI (2003) \\
\hline India & 7 & 35 states and territories & ISIC & Labor & MoSPI (2021) \\
\hline Indonesia & 14 & 33 provinces and districts & KBLI & Labor & BPS (2020) \\
\hline Iran & 2 & 31 NUTS-2 regions & ISIC adapted & Census & SCI (2011) \\
\hline Italy & 6 & 21 NUTS-2 regions & NACE & Labor & ISTAT (2019) \\
\hline Jamaica & 1 & 14 parishes & ISIC adapted & Census & STATIN (2001) \\
\hline Jordan & 12 & 12 governorates & ISIC & Labor & DOS (2016) \\
\hline Kyrgyzstan & 2 & 9 regions and cities & ISIC adapted & Census & NSC (2009) \\
\hline Laos & 1 & 18 provinces and prefectures & ISIC adapted & Census & LSB (2005) \\
\hline Malaysia & 1 & 15 states and territories & ISIC & Census & DOSM (2000) \\
\hline Mexico & 15 & 32 states and districts & SCIAN & Labor & INEGI (2021) \\
\hline Mongolia & 13 & 22 provinces and districts & ISIC & Labor & NSO (2021) \\
\hline Namibia & 2 & 15 regions & ISIC & Labor & NSA (2021) \\
\hline Nicaragua & 3 & 17 departments and regions & ISIC & Household & INIDE (2021) \\
\hline Palestinian Territories & 1 & 16 governorates & ISIC & Labor & PCBS (2008) \\
\hline Panama & 2 & 13 provinces and regions & ISIC adapted & Labor & INEC $(2021 c)$ \\
\hline Papua New Guinea & 1 & 20 provinces, districts and regions & ISIC adapted & Census & NSO $(2000 b)$ \\
\hline Peru & 16 & 25 regions & ISIC & Household & INEI (2021) \\
\hline Philippines & 1 & 80 provinces & ISIC adapted & Census & PSA (2010) \\
\hline Portugal & 2 & 7 regions & NACE & Census & INE (2011) \\
\hline Rwanda & 2 & 5 provinces and cities & ISIC & Census & NISR (2012) \\
\hline Senegal & 1 & 14 regions & ISIC adapted & Census & ANSD (2013) \\
\hline Slovakia & 17 & 8 regions & NACE & Labor & StatSVK (2020) \\
\hline South Africa & 20 & 9 provinces & $\mathrm{SIC}$ & Labor & Stats SA (2021) \\
\hline South Korea & 19 & 17 provinces and cities & $\mathrm{KSIC}$ & Labor & KLI (2019) \\
\hline Spain & 7 & 19 communities and cities & NACE & Labor & INE (2020) \\
\hline Switzerland & 15 & 26 cantons & NACE & Labor & BfS (2020) \\
\hline Tanzania & 2 & 25 regions & ISIC & Labor & NBS (2021) \\
\hline Thailand & 1 & 76 provinces and cities & ISIC & Census & NSO $(2000 a)$ \\
\hline Togo & 1 & 6 regions & ISIC adapted & Census & INSEED (2010) \\
\hline United Kingdom & 20 & 12 NUTS-1 regions & NACE & Labor & ONS (2021) \\
\hline United States & 19 & 51 states and districts & US Census & Household & USCB (2018) \\
\hline Uruguay & 14 & 19 departments & ISIC & Household & INE $(2021 b)$ \\
\hline Venezuela & 1 & 24 states and districts & ISIC & Census & INE (2001) \\
\hline Vietnam & 2 & 64 provinces and municipalities & ISIC adapted & Census & GSO (2009) \\
\hline Zambia & 1 & 10 provinces & ISIC adapted & Census & ZamStats (2010) \\
\hline
\end{tabular}

Table A1: Summary of available countries

The surveys for Armenia, Benin, Botswana, Cameroon, Guinea, Haiti, Iran, Italy, Kyrgyzstan, Laos, Malaysia, Papua New Guinea, the Philippines, Portugal, Rwanda, Senegal, Thailand, 
Figure A1: Available countries

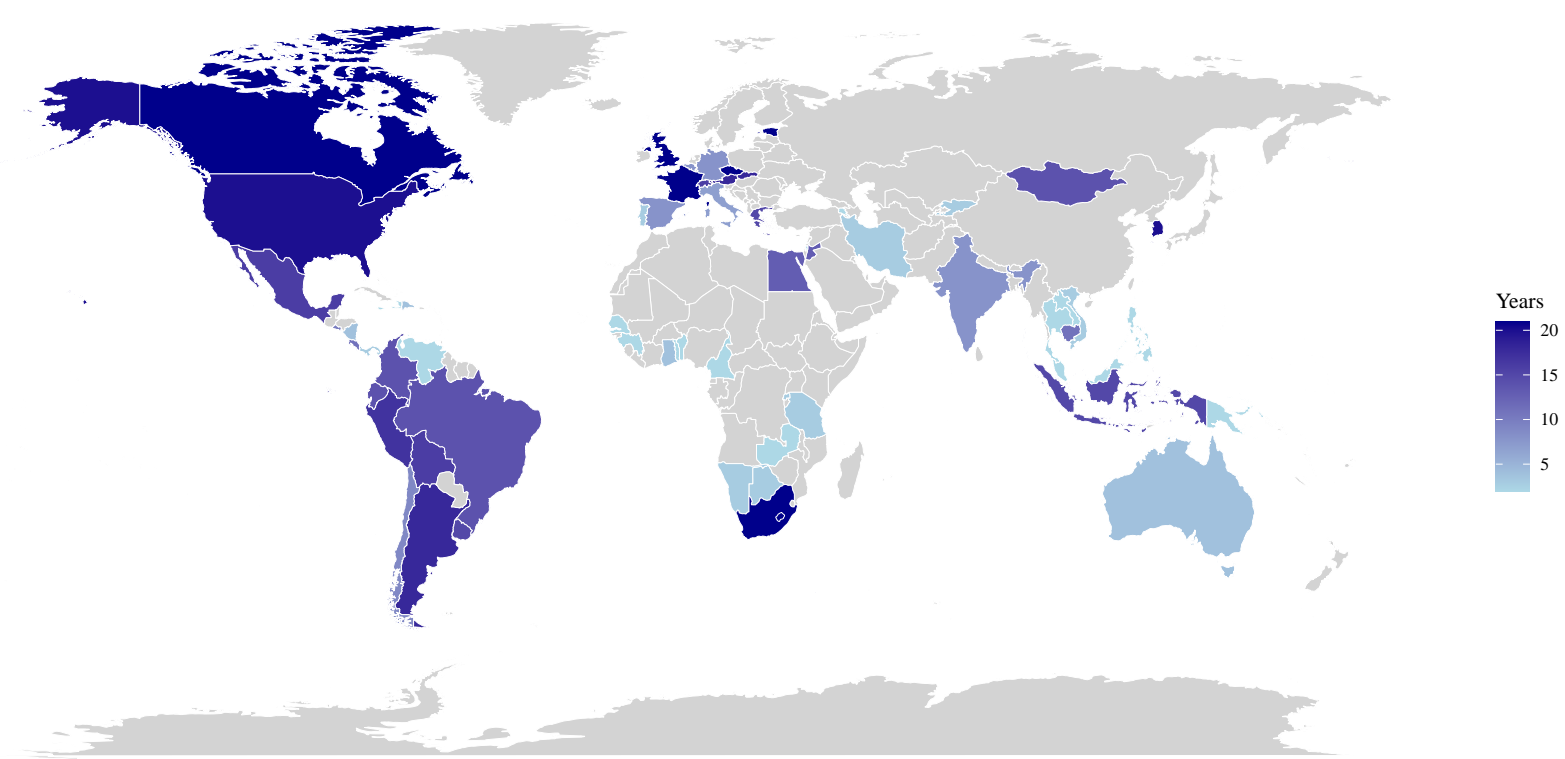

Togo, the USA, Venezuela, Vietnam, and Zambia were provided by the Minnesota Population Center (2019). The surveys for Egypt, Jordan, and the Palestinian Territories were provided by the Economic Research Forum (2020).

\subsection{Data quality checks}

This sections provides some quality checks of the labour and household surveys that we use to assess the regional distribution of industries within a country. These checks demonstrate that overall the data quality of the labor and household surveys is very good and suited for our purposes. We perform the following five tests:

- Figure A2: Does the aggregated data yield the correct industry sector shares of employment on the national level? This ensures that no industry sector is over- or underrepresented. We compare our data to the estimates of sector employment of the International Labour Organization (ILO) (ILO 2020).

- Figure A3: Does the aggregated data yield the correct population shares for each region within the country? This ensures that no region is over- or underrepresented. We compare our data to population data of the Subnational Human Development Index (SHDI) (Smits and Permanyer 2019).

- Figure A4: Is the original data coded correctly? This ensures that we do not use incorrectly coded data or data that uses a different coding scheme than assumed. We compare our data to the coding schemes of the International Standard Industrial Classification (ISIC) (UNSD 2008).

- Figure A5: Is transferring the original coding scheme into the corresponding ISIC scheme causing too much duplication? When the original coding scheme is not as detailed as the ISIC scheme, some respondents are attributed to more than one ISIC category. This duplication should be kept to a minimum.

- Figure A6: Is the aggregated data based on enough respondents? This ensures that our data is robust. 
Figure A2: Employment shares by national industry sector

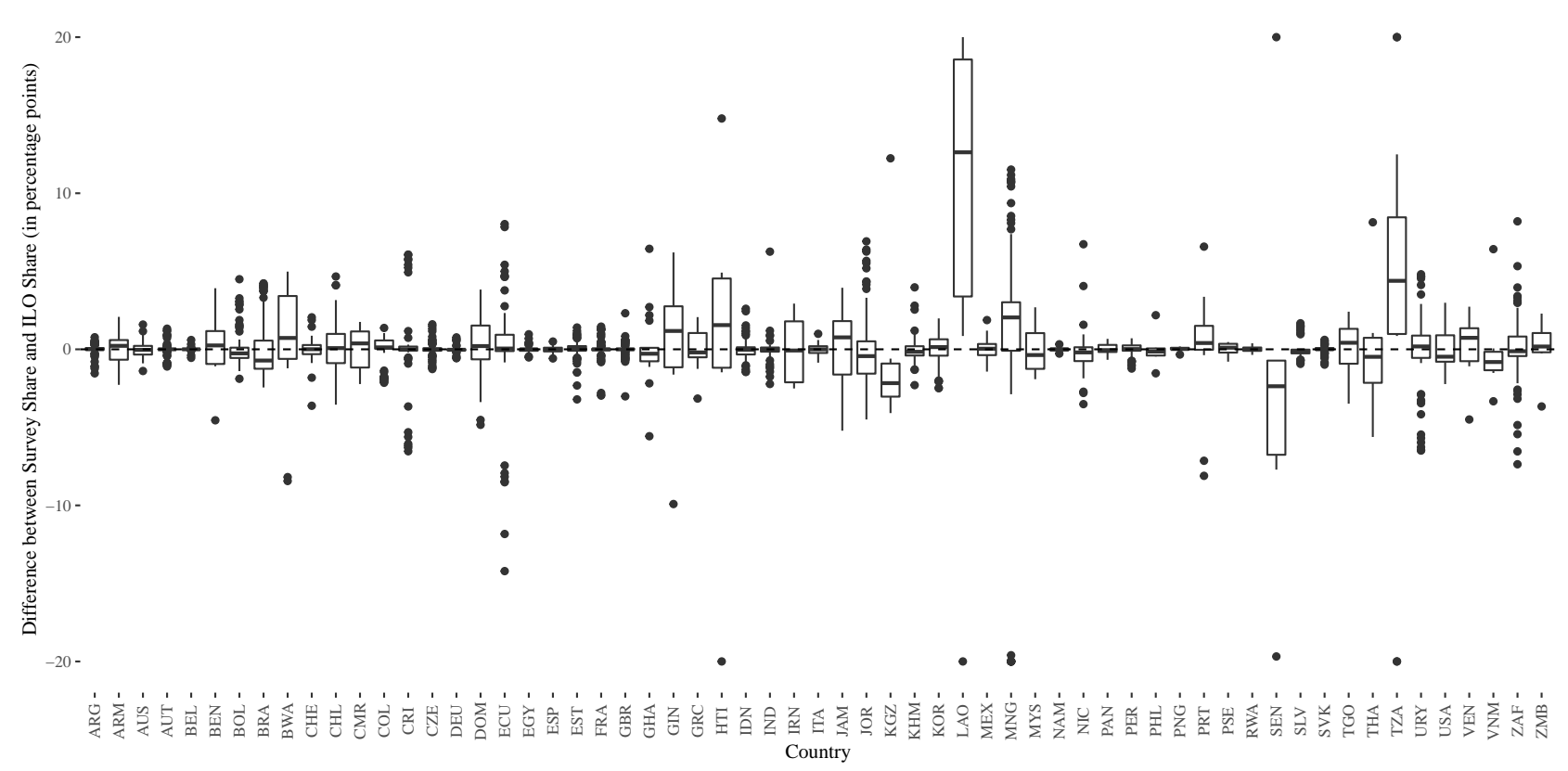

Ideally, the shares should match exactly. In some countries such as Laos and Tanzania, subsistence pastoral farmers are not included in the labour surveys, which explains the large difference to the ILO data.

Figure A3: Population shares by region

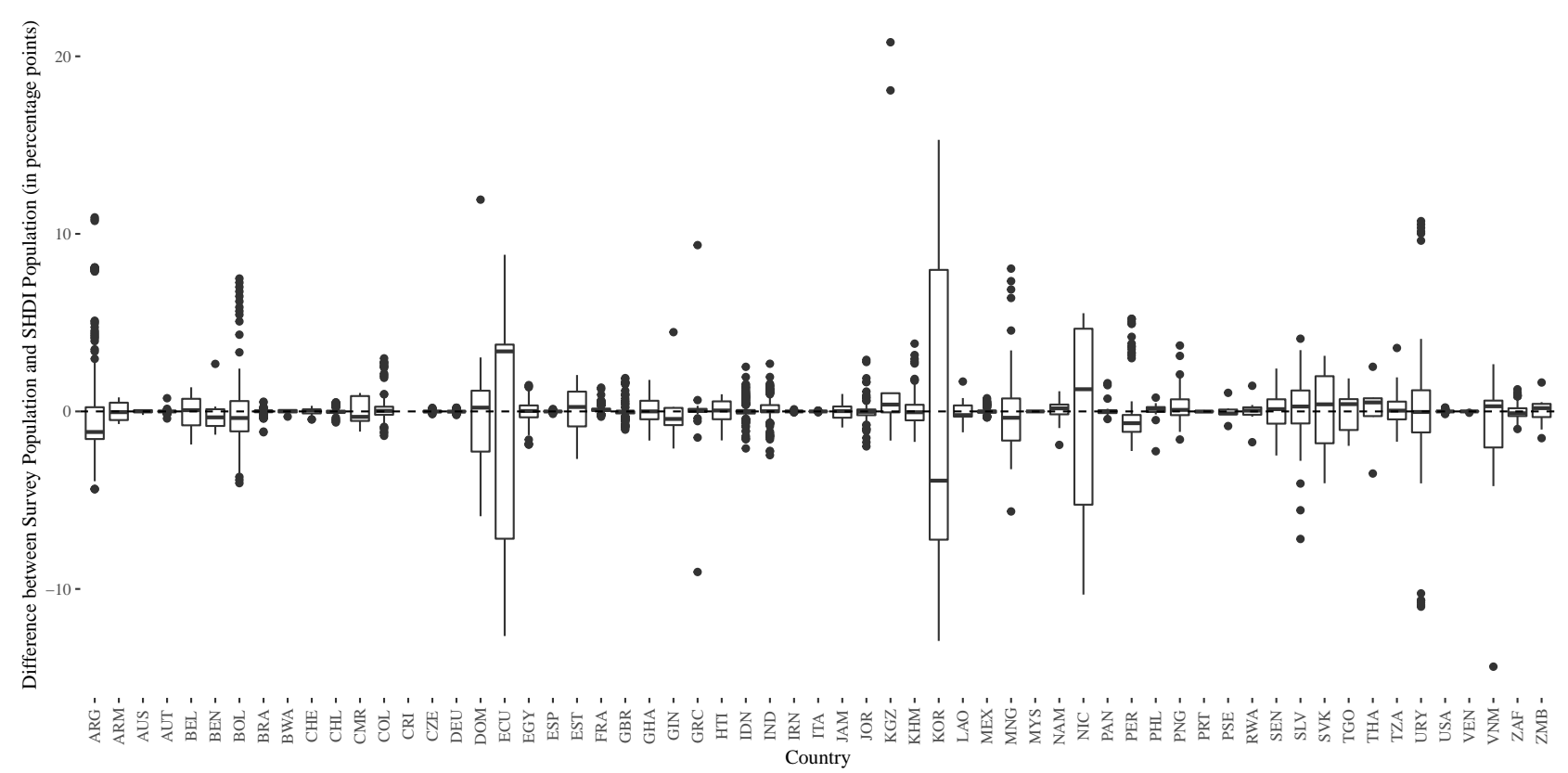

Ideally, the shares should match exactly. For most regions, the shares we have closely resemble the population shares calculated from the SHDI dataset. 
Figure A4: Share of incorrect industry codes

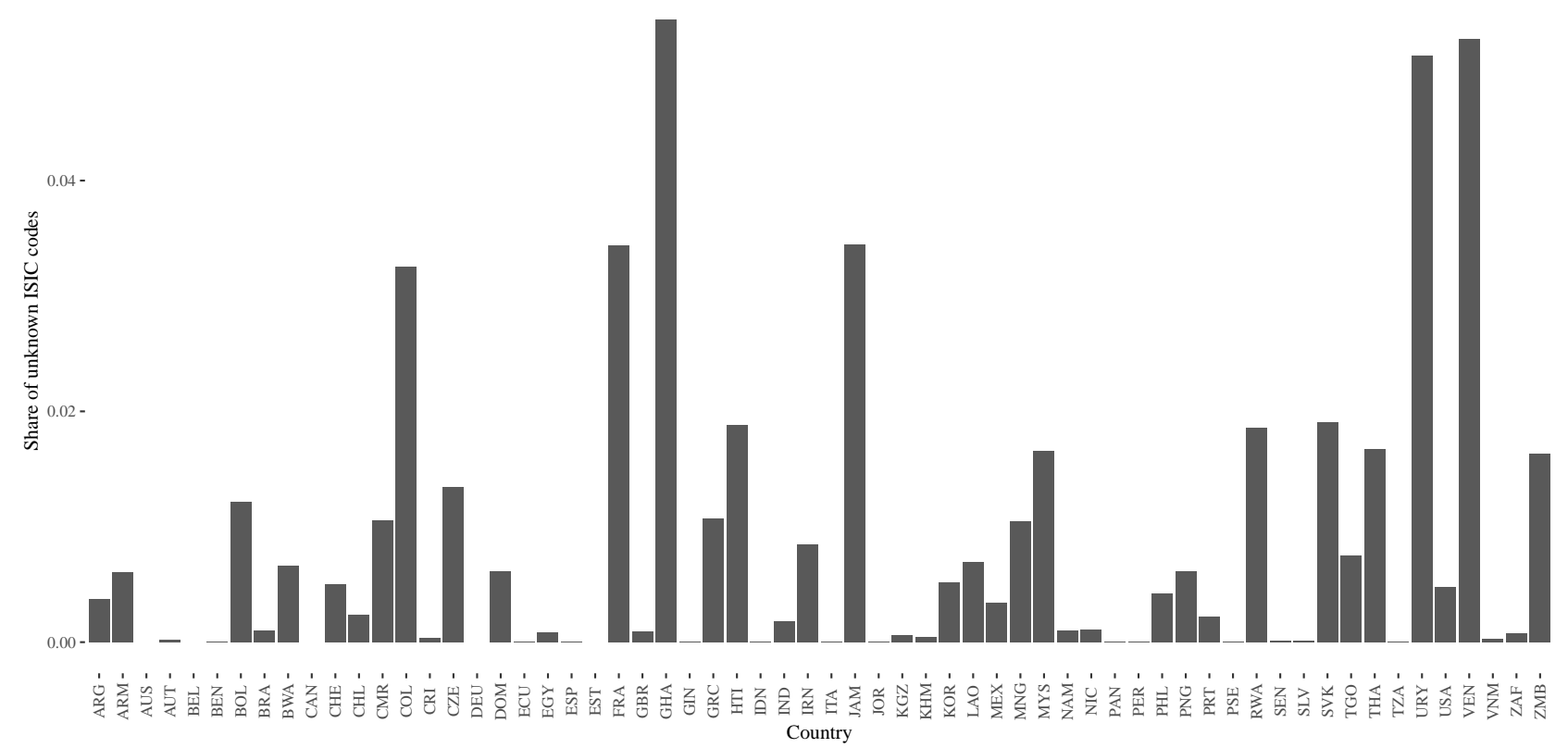

Ideally, there should be no incorrect ISIC codes. However, some countries use special categories that cannot be transferred into standard ISIC schemes. An example is Bolivia, which has a unique code for professional football players. Other countries suppress the codes of certain respondents. We treat these codes as NAs.

Figure A5: Ratio of duplicated respondents

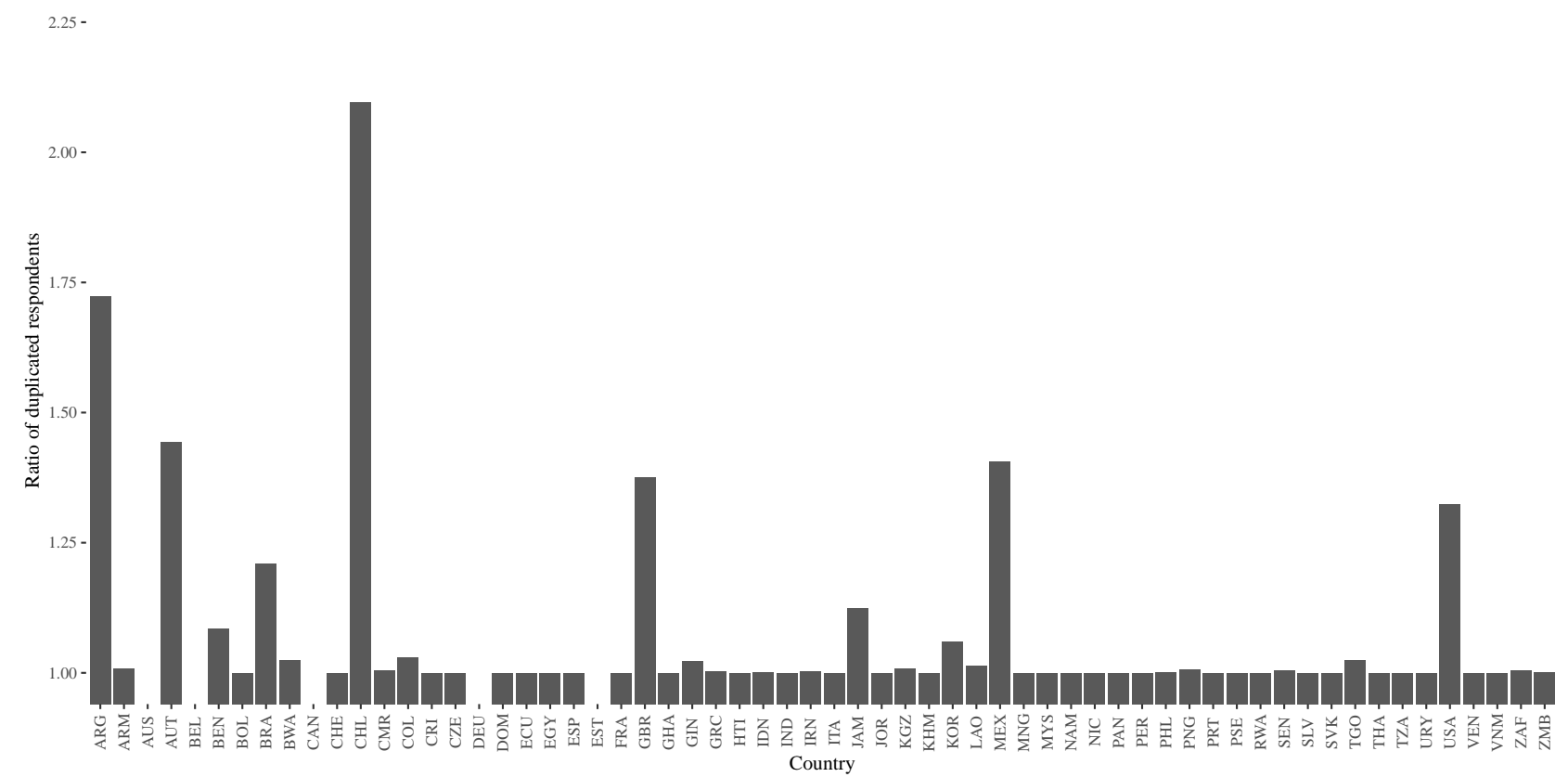

When the original coding scheme is different than the standard ISIC schemes, we use official correspondence tables. Sometimes, these original coding schemes are not as detailed as the corresponding ISIC scheme, which causes the duplication of respondents (who will be attributed more than one ISIC category). The ratio should ideally be 1 , which means that there are no duplicates. In Australia, Belgium, Canada, Germany, and Estonia, the calculation of duplicates is not possible due to technical reasons. However, the ratio of duplicates is close to 1 in these countries. 
Figure A6: Share of regions with few workers

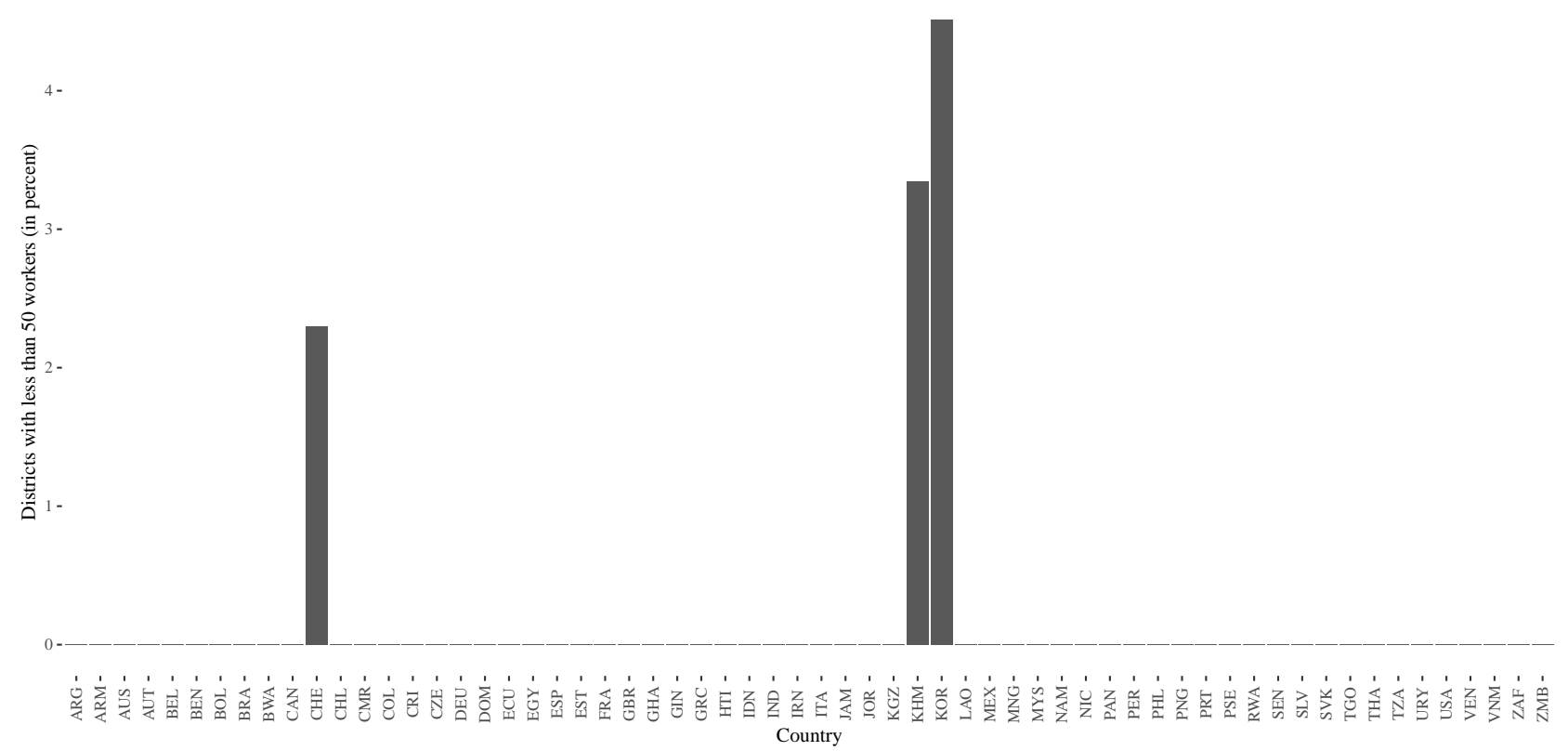

Ideally, the survey would include a large number of workers for each region. However, this is not the case in countries with many first level administrative divisions relative to their population such as Switzerland or Cambodia. In Korea, the labor survey is a panel survey with a low number of respondents. We drop regions if we have fewer than 50 workers to calculate the competitiveness measures.

\subsection{Additional Evidence}

Figure A7: Correlation between the four measures

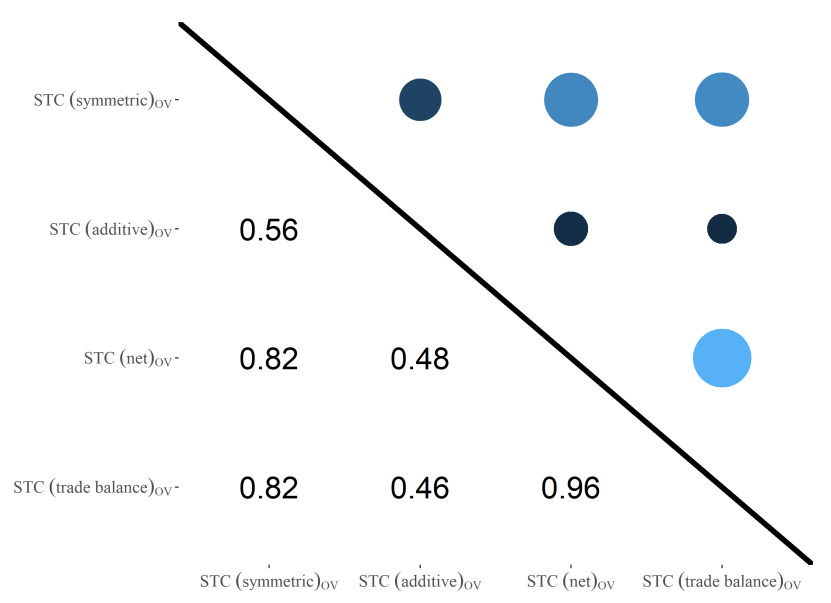


Figure A8: Sectoral competitiveness by region in South Korea

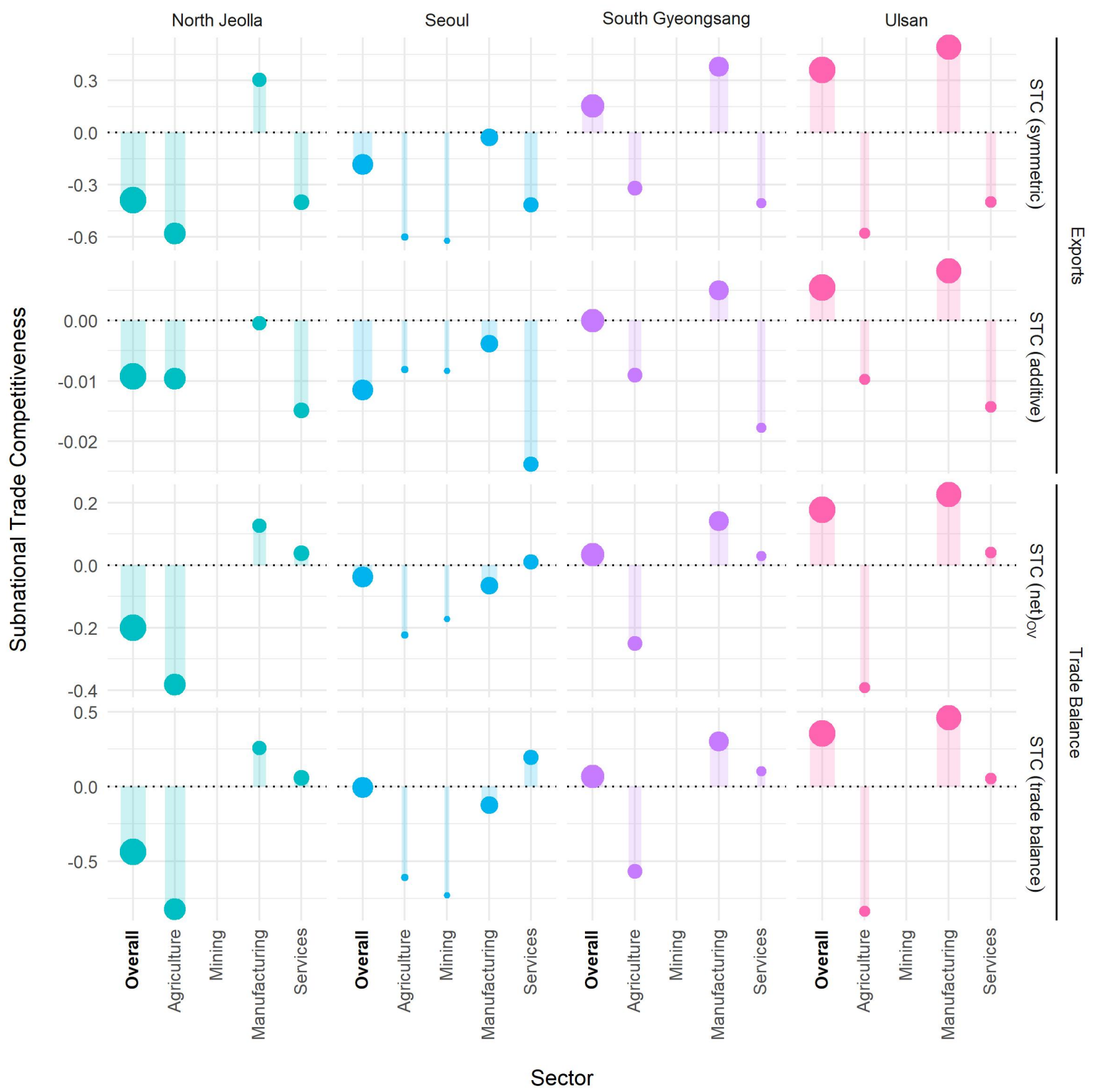

Note: Data for the year 2018. 


\section{Appendix References}

ABS, Australian Bureau of Statistics. 2021. "Census 2006, 2011, and 2016.".

URL: https://www.abs.gov.au/websitedbs/D3310114.nsf/home/About+TableBuilder

ANSD, Agence nationale de la Statistique et de la Démographie (Senegal). 2013. "Grand Census 2013 of Population, Housing, Agruculture, Livestock, and Farming.".

URL: https://international.ipums.org/

BfS, Bundesamt für Statistik (Switzerland). 2020. "Die schweizerische Arbeitskräfteerhebung (SAKE) 2001-2018.".

URL: $\quad$ Https://www.bfs.admin.ch/bfs/de/home/dienstleistungen/forschung/zuganganonymisierte-einzeldaten.html

BPS, Badan Pusat Statistik (Indonesia). 2020. "National Labor Force Survey 2000-2015.".

URL: https://www.bps.go.id/

BUCREP, Bureau Central des Recensements et des Études de Population (Cameroon). 2005. "Third General Census of Population and Housing.".

URL: https://international.ipums.org/

CAPMAS, Central Agency for Public Mobilization and Statistics (Egypt). 2017. "Labor Force Survey (LFS) 2006-2017.".

URL: http://erf.org.eg/data-portal/

CSO, Czech Statistical Office. 2021. "Czech Labour Survey 2000-2019.”.

URL: https://www.czso.cz/csu/czso/4-contacts

DANE, Departamento Administrativo Nacional de Estadística de Colombia. 2021. "Gran Encuesta Integrada de Hogares (GEIH) 2007-2019.".

URL: http://microdatos.dane.gov.co/index.php/catalog

DESTATIS, Statitisches Bundesamt (Germany). 2020. "Mikrozensus 2000-2018.".

URL: https://www.forschungsdatenzentrum.de/de/haushalte/mikrozensus

DIGESTYC, Dirección General de Estadística y Censos de El Salvador. 2021. "Encuesta de Hogares de Propósitos Múltiples 2008-2016.”.

URL: http://digestyc.microdatahub.com/index.php/catalog

DOS, The Hashemite Kingdom of Jordan, Department of Statistics (DOS). 2016. "Employment and Unemployment Survey (EUS) 2004-2016.".

URL: http://erf.org.eg/data-portal/

DOSM, Department of Statistics Malaysia. 2000. "2000 Population and Housing Census.”.

URL: https://international.ipums.org/

Economic Research Forum. 2020. "ERF Micro Data Catalogue (NADA).".

URL: http://erf.org.eg/data-portal/

ELSTAT, Hellenic Statistical Authority. 2021. "Labour Force Survey 2006-2019.”.

URL: https://www.statistics.gr/en/public-use-files

GSO, General Statistics Office of Vietnam. 2009. "Population and Housing Census 1999 \& 2009.".

URL: https://international.ipums.org/ 
GSS, Ghana Statistical Service. 2021. "Ghana Living Standards Survey 2005, 2012, and 2017.”. URL: https://www2.statsghana.gov.gh/nada/index.php/catalog

IBGE, Instituto Brasileiro de Geografia e Estatística. 2021. "Pesquisa Nacional por Amostra de Domicílios (PNAD) 2002-2015.".

URL: https://www.ibge.gov.br/estatisticas/sociais/educacao/9127-pesquisa-nacional-poramostra-de-domicilios.html $?=8 t=$ microdados

IHSI, Institute Haïtien de Statistique et d'Informatique. 2003. "Recensement General de la Population et de l'Habitat 2003.".

URL: https://international.ipums.org/

INDEC, Instituto Nacional de Estadística y Censos de la República Argentina. 2021. "Encuesta Permanente de Hogares.".

URL: https://www.indec.gob.ar/indec/web/Institucional-Indec-BasesDeDatos

INE, Instituto Nacional de Estadística (Bolivia). 2021a. "Encuesta de Hogares 2004-2019.".

URL: https://www.ine.gob.bo/index.php/censos-y-banco-de-datos/censos/bases-de-datosencuestas-sociales/

INE, Instituto Nacional de Estadística (Spain). 2020. "Encuesta de Población Activa 20062019.".

URL: https://www.ine.es/en/prodyser/microdatos_en.htm

INE, Instituto Nacional de Estadística (Uruguay). 2021b. "Encuesta Continua de Hogares 20062019.".

URL: http://www.ine.gub.uy/web/guest/encuesta-continua-de-hogares1

INE, Instituto Nacional de Estadística (Venezuela). 2001. "XIII Censo General de Población y Vivienda.".

URL: https://international.ipums.org/

INE, Instituto Nacional de Estatística (Portugal). 2011. "Receseamento Geral da População 2001 \& 2011.".

URL: https://international.ipums.org/

INEC, Instituto Nacional de Estadística y Censos (Costa Rica). 2021a. "Encuesta Continua de Empleo 2010-2019.”.

URL: http://sistemas.inec.cr/pad5/index.php/catalog/REGECE

INEC, Instituto Nacional de Estadística y Censos (Ecuador). 2021b. "Encuesta Nacional de Empleo, Desempleo y Subempleo 2007-2019.".

URL: http://aplicaciones3.ecuadorencifras.gob.ec/BIINEC-war/index.xhtml

INEC, Instituto Nacional de Estadística y Censos (Panama). 2021c. "Encuesta de Mercado Laboral 2012-2017.".

URL: http://www.inec.gob.pa/dbnew/pass/indice.html

INEGI, Geografía e Informática (Mexico), Instituto Nacional de Estadística. 2021. "Encuesta Nacional de Ocupación y Empleo (ENOE), 2005-2019.".

URL: https://www.inegi.org.mx/programas/enoe/15ymas/?ps=Microdatos

INEI, Instituto Nacional de Estadística e Informática de Perú. 2021. "Encuesta Nacional de Hogares 2004-2019.".

URL: http://iinei.inei.gob.pe/microdatos/Consulta_por_Encuesta.asp 
INIDE, Instituto Nacional de Información de Desarrollo de Nicaragua. 2021. "Encuesta Nacional de Hogares sobre Medición de Nivel de Vida 2005, 2012, and 2014.".

URL: http://www.inide.gob.ni/bibliovirtual/basesdatos.htm

INS, Institut National de la Statistique (Guinea). 2014. "Third General Census of the Population and Inhabitants.".

URL: https://international.ipums.org/

INSAE, L'Institut National de la Statistique et de l'Analyse Economique (Benin). 2013. "Fourth Population and Habitation Census.".

URL: https://international.ipums.org/

INSEE, Institut National de la Statistique et des Etudes Economiques (France). 2020. "Enquête Emploi en continu 2000-2019.".

URL: https://commande.progedo.fr/fr/utilisateur/connexion

INSEED, Institut National de la Statistique et des Etudes Economiques et Démographiques. 2010. "General Census of the Population and Habitat 2010.".

URL: https://international.ipums.org/

ISTAT, National Institute of Statistics (Italy). 2019. "Labour Force Survey 2014-2019.".

URL: https://international.ipums.org/

KLI, Korea Labor Institute. 2019. “Korean Labor \& Income Panel Study 2000-2018.”.

URL: https://www.kli.re.kr/klips_eng/index.do

LSB, Lao Statistics Bureau. 2005. "2005 Population and Housing Census.”.

URL: https://international.ipums.org/

MDSF, Ministerio de Desarrollo Social y Familia de Chile. 2021. "Encuesta de Caracterizacion Socioeconomica Nacional (CASEN) 2000-2017.".

URL: http://observatorio.ministeriodesarrollosocial.gob.cl/encuesta-casen

Minnesota Population Center. 2019. "Integrated Public Use Microdata Series, International: Version 7.2.". Version Number: 7.2 type: dataset.

URL: https://www.ipums.org/projects/ipums-international/d020.V7.2

MoSPI, Ministry of Statistics \& Programme Implementation (India). 2021. "Employment and Unemployment Survey, 2000, 2004, 2005, 2006, 2008, 2010, and 2012.".

URL: http://microdata.gov.in/nada43/index.php/catalog/127/related_materials

NBS, Tanzania National Bureau of Statistics. 2021. "Intergrated Labour Force Survey 2006 \& 2014.".

URL: https://nbs.go.tz/tnada/index.php/catalog/31

NIS, National Institute of Statistics (Cambodia). 2020. "Socio-Economic Survey 1999-2017.”.

URL: https://www.nis.gov.kh/index.php/en/

NISR, National Institute of Statistics of Rwanda. 2012. "Population and Housing Census 2002 \& 2012.".

URL: https://international.ipums.org/

NSA, Namibia Statistics Agency. 2021. "Labour Force Survey 2013 \& 2016.".

URL: https://nsa.org.na/microdata1/index.php/catalog 
NSC, National Statistical Committee of the Kyrgyz Republic. 2009. "Census of Population and Housing of the Kyrgyz Republic, 1999 \& 2009.".

URL: https://international.ipums.org/

NSO, National Statistical Office of Mongolia. 2021. "Labour Force Survey 20003-2018.".

URL: http://web.nso.mn/nada/index.php/catalog/LFS

NSO, National Statistical Office of Thailand. 2000a. "The 2000 Population and Housing Census of Thailand.".

URL: https://international.ipums.org/

NSO, National Statistics Office of Papua New Guinea. 2000b. "National Census 2000.”.

URL: https://international.ipums.org/

NSS, National Statistical Service of the Republic of Armenia. 2011. "The 2011 Population and Housing Census of the Republic of Armenia.."

URL: https://international.ipums.org/

ONE, Oficina Nacional de Estadística de la República Dominicana. 2021. "Encuesta de Hogares de Propositos Multiples 2009, 2013, and 2015.".

URL: https://www.one.gob.do/

ONS, Office for National Statistics (United Kingdom). 2021. "Quarterly Labour Force Survey 2000-2019.".

URL: https://beta.ukdataservice.ac.uk/

PCBS, Palestinian Central Bureau of Statistics. 2008. "Labor Force Survey (LFS) 2008.".

URL: http://erf.org.eg/data-portal/

PSA, Philippine Statistics Authority. 2010. "2010 Census of Population and Housing.”.

URL: https://international.ipums.org/

SCI, Statistical Center of Iran. 2011. "National Population and Housing Census 2006 \& 2011.”. URL: https://international.ipums.org/

StatAustria, Statistik Austria. 2020. "Mikrozensus 2003-2019.".

URL: https://data.aussda.at/dataverse/statistikaustria

StatBel, Belgian Statistical Office. 2020. "Labour Force Survey 2013-2019.".

URL: https://statbel.fgov.be/en/about-statbel/what-we-do/microdata-research

StatEst, Statistikaamet (Estonia). 2020. "Labour Force Survey 2000-2019.”.

URL: https://www.stat.ee/en/find-statistics/request-statistics/request-microdata-research

STATIN, Statistical Institute of Jamaica. 2001. "Population Census 2001.”.

URL: https://international.ipums.org/

Stats SA, Statistics South Africa. 2021. "Quarterly Labour Force Survey 2000-2019.”.

URL: https://www.datafirst.uct.ac.za/dataportal/index.php/catalog/499/get_microdata

StatsBots, Statistics Botswana. 2011. "Population and Housing Census 2001 \& 2011.".

URL: https://international.ipums.org/

StatsCAN, Statistics Canada. 2021. "Labour Force Survey 2000-2019.".

URL: https://www.statcan.gc.ca/eng/help/microdata 
StatSVK, Statistical Office of the Slovak Republic. 2020. "Slovakian Labour Force Survey 20032019.".

URL: https://slovak.statistics.sk/wps/portal/ext/services/

USCB, U.S. Census Bureau. 2018. “American Community Survey 2000-2018.”.

URL: https://international.ipums.org/

ZamStats, Zambia Statistics Agency. 2010. "2010 Census of Population and Housing.".

URL: https://international.ipums.org/ 